\title{
BioMass PDU Electrical Design Study UPDATE
}

Jake P. Gentle

Kurt S. Myers

Thomas L. Baldwin

Jason W. Bush

April 2012

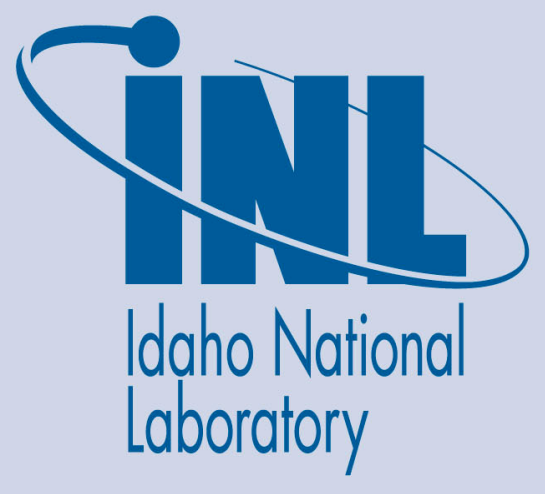

The INL is a U.S. Department of Energy National Laboratory operated by Battelle Energy Alliance 
INL/EXT-12-25722

\title{
BioMass PDU Electrical Design Study UPDATE
}

\author{
Jake P. Gentle \\ Kurt S. Myers \\ Thomas L. Baldwin \\ Jason W. Bush
}

April 2012

\author{
Idaho National Laboratory \\ Idaho Falls, Idaho 83415 \\ http://www.inl.gov
}

Prepared for the

U.S. Department of Energy

Assistant Secretary for Energy Efficiency and Renewable Energy

Under DOE Idaho Operations Office

Contract DE-AC07-05ID14517 


\section{DISCLAIMER}

This information was prepared as an account of work sponsored by an agency of the U.S. Government. Neither the U.S. Government nor any agency thereof, nor any of their employees, makes any warranty, expressed or implied, or assumes any legal liability or responsibility for the accuracy, completeness, or usefulness, of any information, apparatus, product, or process disclosed, or represents that its use would not infringe privately owned rights. References herein to any specific commercial product, process, or service by trade name, trade mark, manufacturer, or otherwise, does not necessarily constitute or imply its endorsement, recommendation, or favoring by the U.S. Government or any agency thereof. The views and opinions of authors expressed herein do not necessarily state or reflect those of the U.S. Government or any agency thereof. 



\section{SUMMARY}

The BioMass Process Demonstration Unit (PDU) electrical system is used for the power distribution and control of the many motors and process required loads. Study requirements include a complete system analysis and equipment evaluation, which includes conductor sizing, transformer sizing, breaker and fuse sizing, short-circuit analysis, load-flow analysis, protective-device coordination, arc-flash-hazard analysis, and a multi-state code and grounding review. The SKM System Analysis, Inc., software package was used to model the electrical system, and the input data used can be found in Appendix A. In addition, an electrical inspection walk thru was performed for code compliance, and the findings can be found in emails located in Appendix G. A complete set of ANSI A_Fault drawings are located in Appendix I.

The A_FAULT package was used to calculate the short-circuit analysis. The short-circuit analysis report can be found in Appendix B and shows a variety of information, but the main points to observe are the values from the three-phase fault, the single-line to ground fault, and their $\mathrm{X} / \mathrm{R}$ ratio values, respectably.

Load flow analyses are performed to ensure that the electrical system can transfer power from the source to the loads in a stable and reliable manner. Load flows also help determine whether transformers and conductors are properly sized or if they will become overloaded. The results from the load flow analysis report can be found in Appendix $\mathrm{C}$ and show that some equipment could be overloaded at full load levels. The load-flow currents are used to monitor the ampacity rating limits of the cables to be sure that the sizing of each conductor was properly done. The following conductors have the potential to be overloaded as is shown in the equipment evaluation report found in Appendix F.

- Both motor control center (MCC)1 cable (CBL)21 and MCC1 CBL22 have a design ampacity value of 301.51 amps and a 4/0 American wire guage (AWG) cable rated at 230 amps. Consider upsizing these cables to a $350-\mathrm{kcmil}-\mathrm{size}$ cable rated at $310 \mathrm{amps}$.

- $\quad$ MCC1 CBL5 has a design ampacity value of 544.53 amps and a 500 kcmil cable rated at 380 amps. Consider upsizing this cable to a 1000 -kcmil-size cable rated at 545 amps.

- $\quad$ MCC2 CBL27 has a design ampacity value of 75.38 amps and an $8 \mathrm{AWG}$ cable rated at $50 \mathrm{amps}$. Consider upsizing this cable to a 4/0-AWG-size cable rated at 85 amps. 
- Both MCC4 CBL48 and MCC4 CBL50 have a design ampacity value of 376.89 amps and a $350 \mathrm{kcmil}$ cable rated at 310 amps. Consider upsizing these cables to a $500-\mathrm{kcmil}-\mathrm{size}$ cable rated at 380 amps.

- MCC4 CBL5 has a design ampacity value of 476.99 amps and a $500 \mathrm{kcmil}$ cable rated at $380 \mathrm{amps}$. Consider upsizing this cable to an $800 \mathrm{kcmil}$ size cable rated at 490 amps.

- MCC1 transformer (Xfrmr)1 has a design ampacity value of $11.25 \mathrm{amps}$ and an ampacity rating of $10.8 \mathrm{amps}$. Consider upsizing this transformer to a 15-KVA-size rated for 18 amps.

- MCC2 Xfrmr0* has a design ampacity value of 21.46 amps and an ampacity rating of 10.8 amps. Consider upsizing this transformer to a $22.5 \mathrm{kVA}$ size rated for $27 \mathrm{amps}$. *Note: It has been determined that the current cabinet in which this transformer is located can support up to a $15 \mathrm{KVA}$ transformer. A $22.5 \mathrm{kVA}$ transformer would require a new cabinet. The control-trailer load (approximately $30 \mathrm{amps)}$ is the major load on this transformer and is not connected or at full load at all times; thus, a $15 \mathrm{kVA}$ transformer would suffice for the other loads and it is believed that a $15 \mathrm{kVA}$ transformer would support the control-trailer load, but would have a reduced life because of the overloading incurred during control-trailer loading.

The protective-device coordination study was performed in order to properly determine whether the breakers and fuses were properly sized and the settings appropriately set in order to protect the system. As part of the protective-device coordination, the Computer Aided Plotting for Time Overcurrent Reporting (CAPTOR) study module was used to plot the time-current coordination (TCC) characteristics of the electrical components to ensure that they protect the different electrical apparatus from possible overload and short-circuit currents. TCC report drawings can be found in Appendix D. This system has been protected with the functionality of the electrical components and the safety of the equipment and personnel working in the area in mind. Coordination has been done to isolate the area of abnormality and not interrupt the performance and operation of the rest of the system. However, our model (see Equipment Evaluation Report in Appendix F) indicates that a possibility for failure exists for breakers MCC1 DC-5, MCC4 AL-2, MCC4 CRF-1, MCC4 DC-1, MCC4 PM-2, MCC4 PMC-1, and MCC4 SC-3.

An arc-flash analysis has been performed on the BioMass PDU electrical system to help provide safety guidance to reduce or prevent injury to workers. The results from the arc flash analysis show four main categories of concern, and the proper clothing and equipment for these categories are identified in section 3.4 as well as in Appendix E.

As part of the BioMass PDU project analysis, a grounding review and multistate code review was performed. As part of this review, it was suggested that the equipment grounding system and the static/lightning protections systems be integrated into one ground wire system. Figure 4 represents the grounded system as applied to the BioMass PDU application. Figure 5 and Figure 6 show multistate codes applicable to this system and a map of NEC adoption by state. 


\section{CONTENTS}

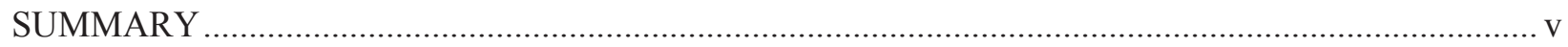

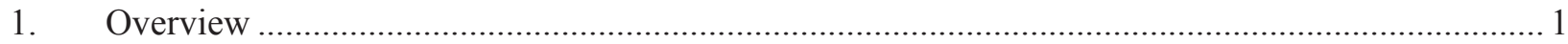

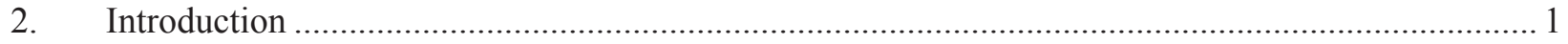

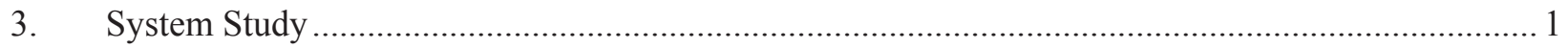

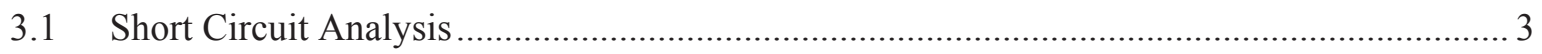

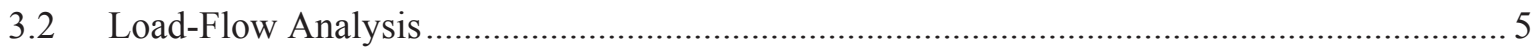

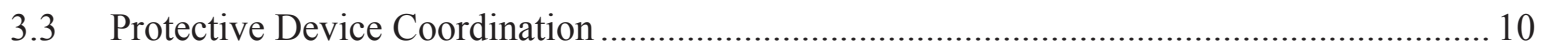

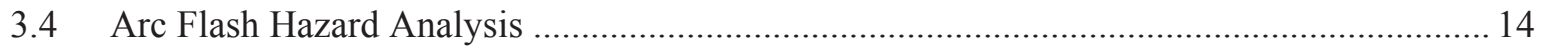

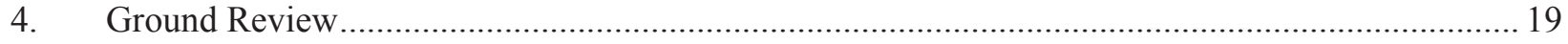

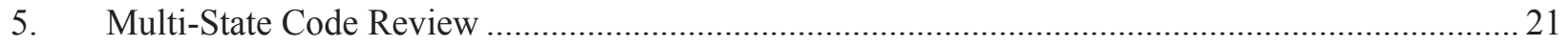

\section{FIGURES}

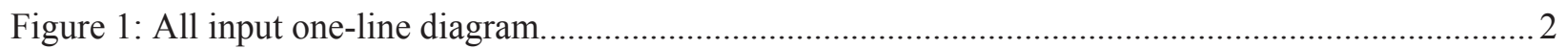

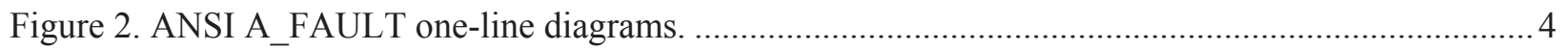

Figure 3. Largest motor TCC drawing for protective-device coordination study................................... 13

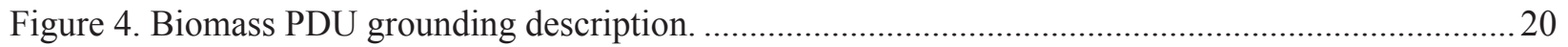

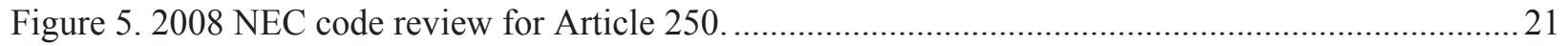

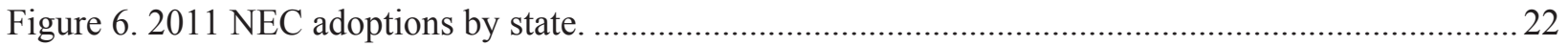

TABLES

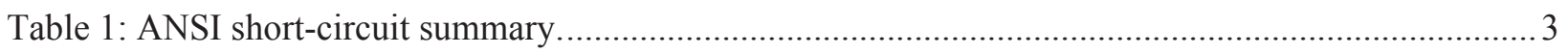

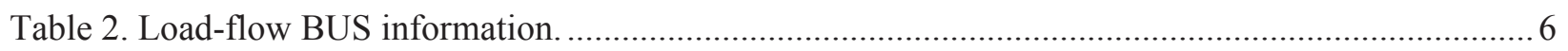

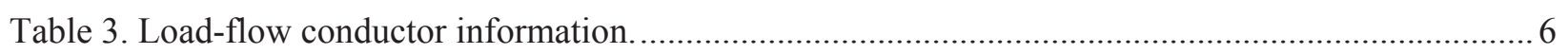

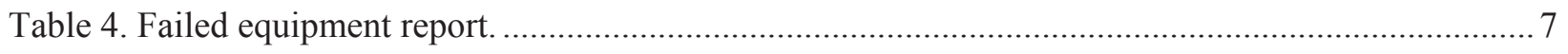

Table 5. Load-flow transformer (XFRMR) and utility information. ...................................................... 8

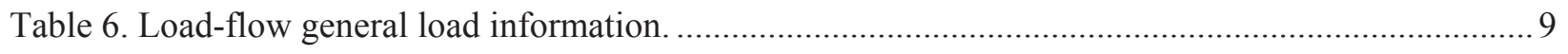

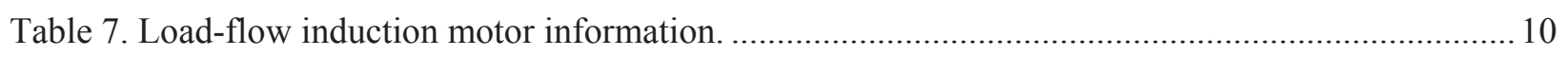

Table 8. Protective-device coordination breaker settings. .................................................................... 11

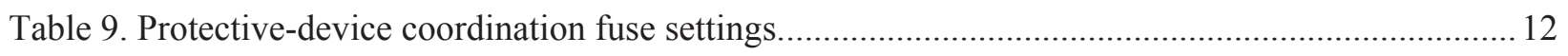

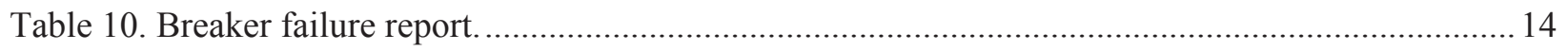


Table 11. Arc-flash personal protective equipment information.

Table 12. Arc-flash analysis results. 


\section{BioMass PDU Electrical Design Study UPDATE}

\section{Overview}

\section{Introduction}

\section{System Study}

The BioMass PDU electrical system is used for the power distribution and control of the many motors and process-required loads. Study requirements include a complete system analysis and equipment evaluation, which includes conductor sizing, transformer sizing, breaker and fuse sizing, short-circuit and load-flow analysis, protective-device coordination, arc-flash hazard analysis, and a multi-state code and grounding review. In addition, an electrical-inspection walk thru was performed for code compliance. The findings can be found in emails located in Appendix G.

Input information for all equipment modeled for the BioMass PDU project can be found in Appendix A. A simple one-line diagram of the electrical system can be seen in Figure 1, and the full set of drawings is located in Appendix H. 


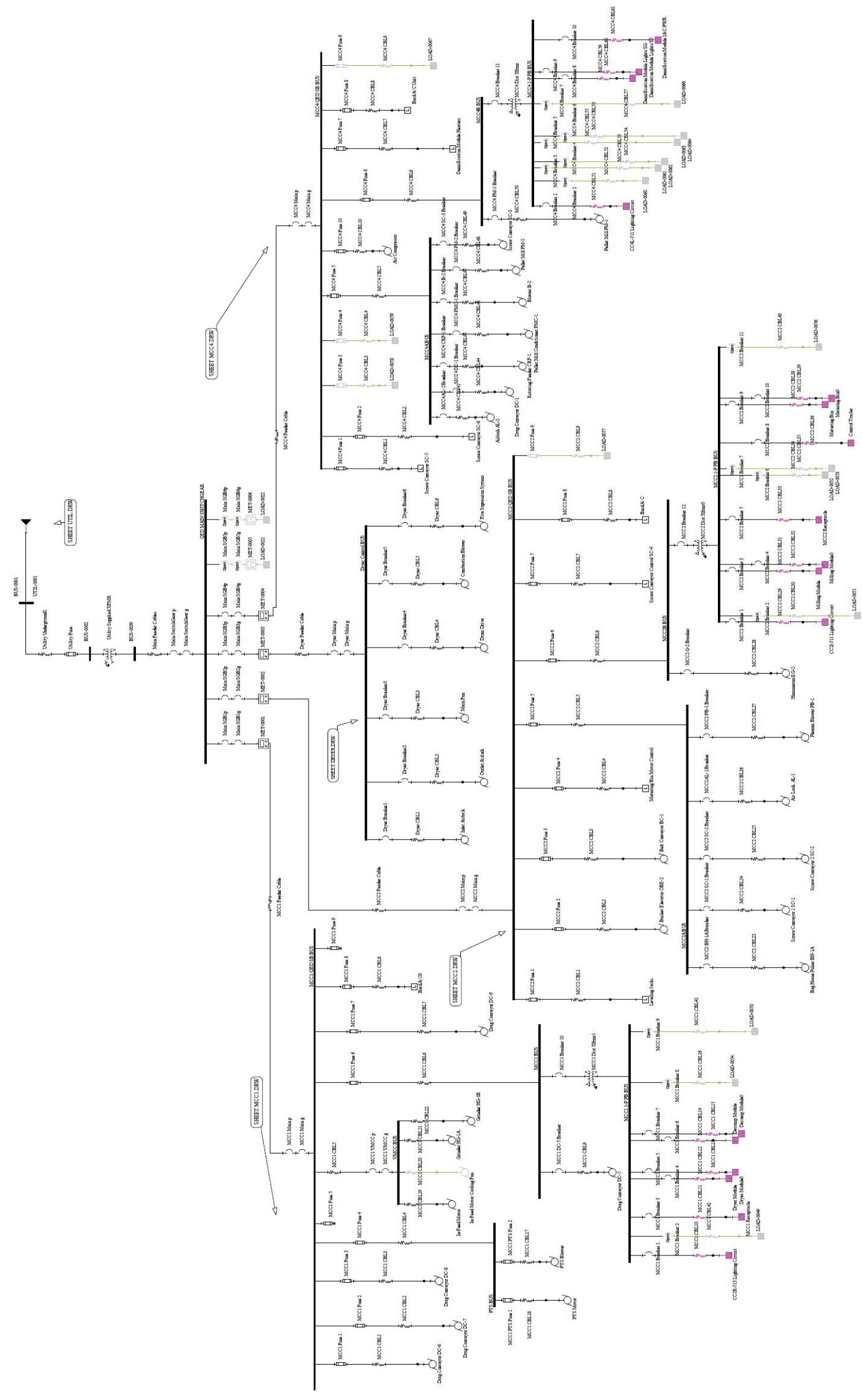

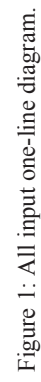




\subsection{Short Circuit Analysis}

The A_FAULT package within the SKM System Analysis, Inc., software package that was used to model the electrical system was used to calculate the short circuit analysis. A_FAULT provides the fault calculations in compliance with ANSI C37 standards. The report shows a variety of information, but the main points to observe are the values from the three-phase fault, the single-line to ground fault, and their reactance/resistance $(\mathrm{X} / \mathrm{R})$ ratio values, respectably.

Detailed information can be found in Appendix B, but Table 1 shows a summary of the model short circuit analysis results for the buses that are considered contributors of short circuit current. There are a total of 60 faulted buses considered as short circuit contributors by ANSI standards as they are modeled in this system. Some of the busses and their respective fault values are shown in the table below.

Table 1: ANSI short-circuit summary.

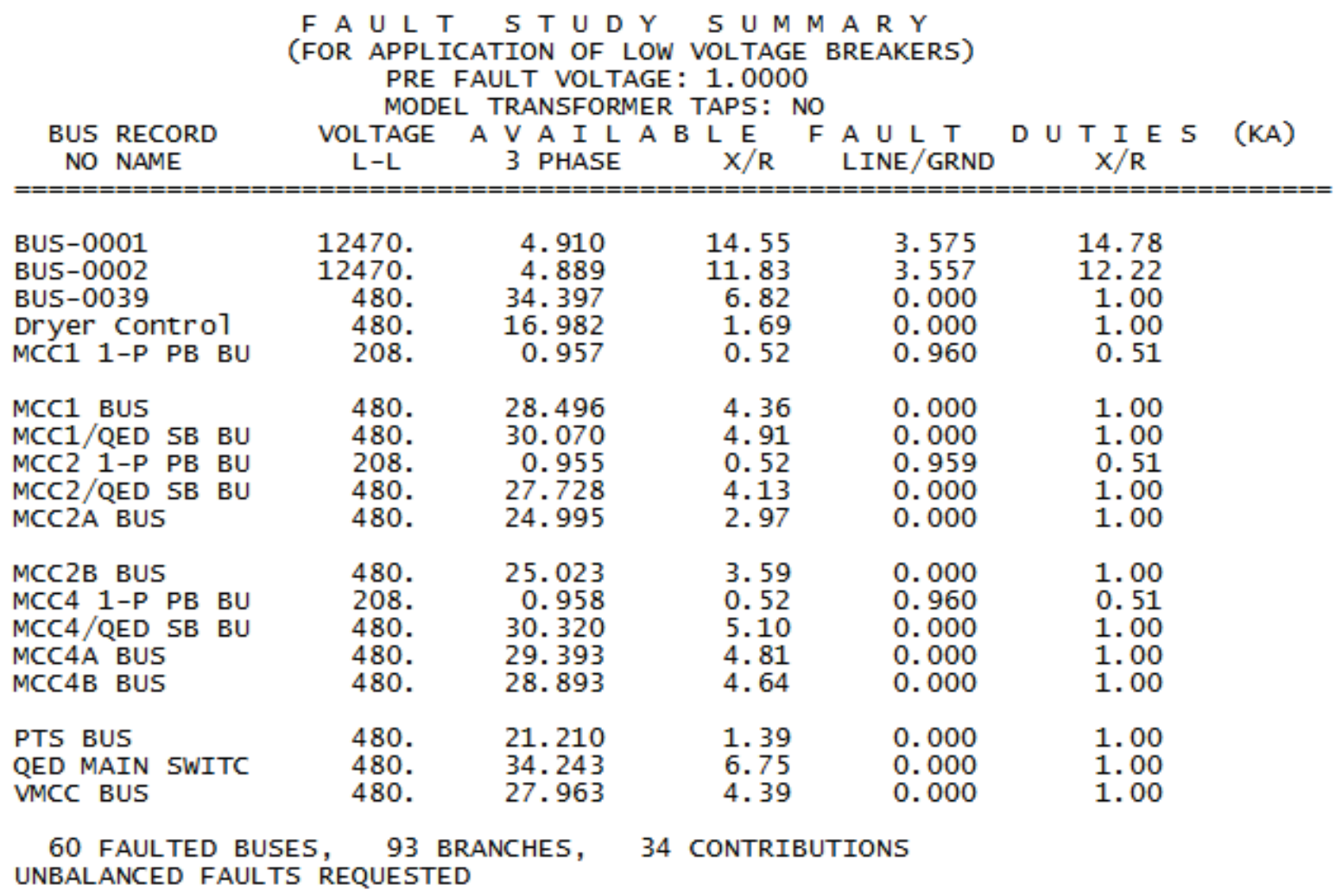



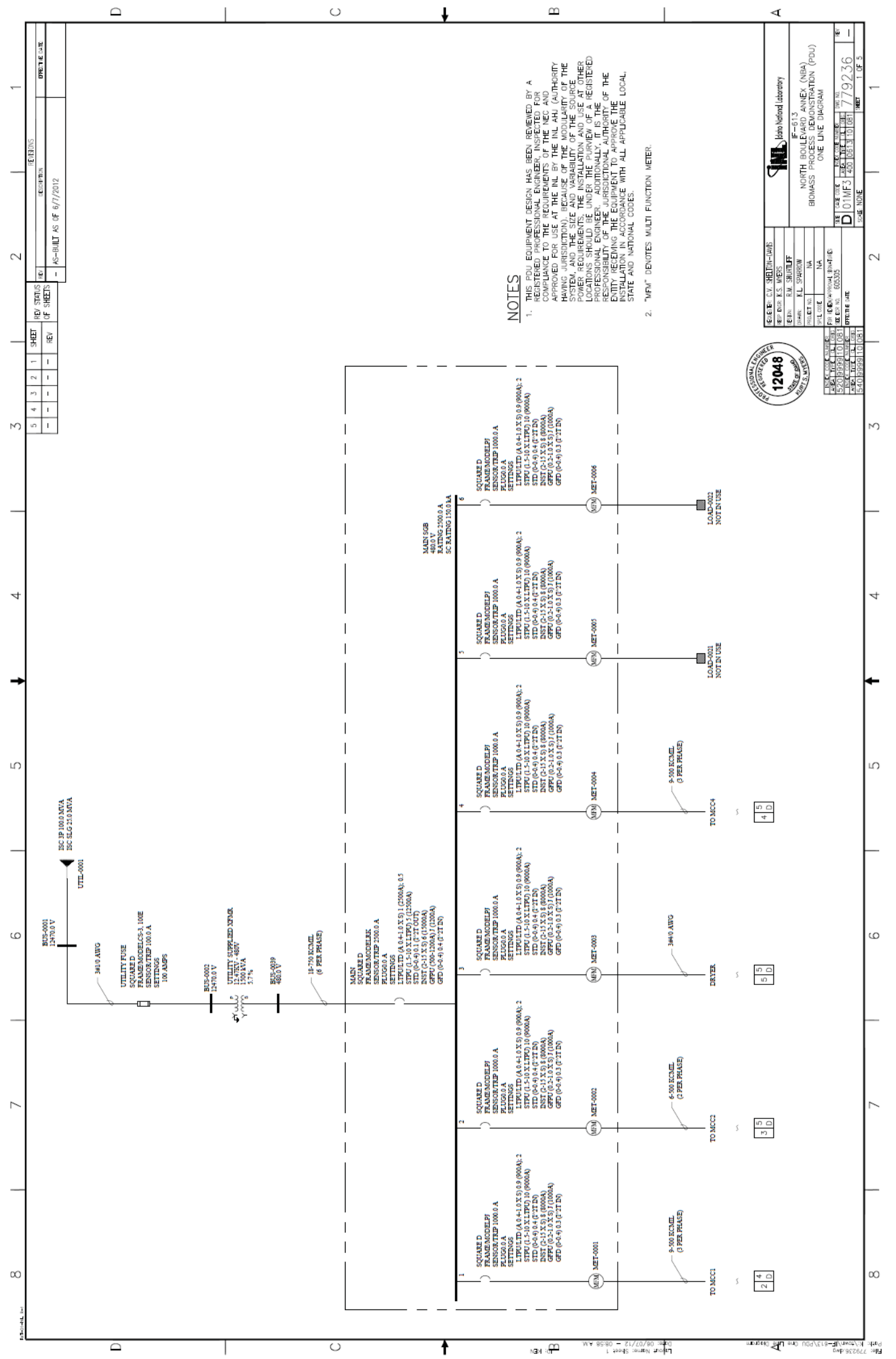
The one-line diagram in Figure 2, above, also shows these values next to the corresponding bus, cables, fuses, breakers, and transformers. A complete set of this drawing can be found in Appendix I. These values were used to determine the magnitude of current available at various selected points of the electrical system when a fault occurs. The three-phase fault condition is used to measure the maximum current that will be seen on the system at the selected point during a fault. The point at which the fault occurs is on the source side of the device. This is done to determine whether or not the appropriate device will be able to interrupt the short-circuit current during fault situations.

The short-circuit study gives the ability to determine if the breakers and fuses are capable of interrupting a fault, as well as verifying the appropriate sizing of the switchgear and bus bar sections.

\subsection{Load-Flow Analysis}

Load-flow analyses are performed to ensure that the electrical system can transfer power from the source to the loads in a stable and reliable manner. Load flows are performed to determine the steadystate operation of the system, as well as calculate the voltage drop on each feeder, bus, and the power flow in all of the branch and feeder circuits within the system. Load flows also help determine whether transformers and conductors are properly sized or they will become overloaded.

The results from the load-flow analysis show that some of the equipment (as specified later in this section) could have the possibility of being overloaded at full load levels; the full-load-flow analysis and the unbalanced system equipment evaluation report can be seen in Appendix C and Appendix F. Table 2 shows the system voltage at the bus, the percent voltage drop at the bus, and the load flow voltage at the bus. However, due to the large size, the table below is only a sample version of the first few buses; for the complete table of all of the buses please see Appendix C, 9.1. 
Table 2. Load-flow BUS information.

\begin{tabular}{|c|c|c|c|c|c|c|c|}
\hline BUS NAME & System Voltage & $(\%)$ VD A & $(\%)$ VD B & $(\%)$ VD C & LF Voltage (V) A & LF Voltage (V) B & LF Voltage (V) C \\
\hline BUS-0001 & 12470 & 1.03 & 1.2 & 1.29 & 7125 & 7113 & 7107 \\
\hline BUS-0002 & 12470 & 1.06 & 1.23 & 1.31 & 7123 & 7111 & 7105 \\
\hline BUS-0009 & 480 & -1.49 & 13.59 & 7.4 & 281 & 239 & 257 \\
\hline BUS-0010 & 480 & -1.64 & 13.41 & 7.23 & 282 & 240 & 257 \\
\hline BUS-0012 & 480 & -1.5 & 13.58 & 7.39 & 281 & 240 & 257 \\
\hline BUS-0015 & 480 & -1.49 & 13.59 & 7.4 & 281 & 239 & 257 \\
\hline BUS-0018 & 480 & -1.4 & 13.71 & 7.48 & 281 & 239 & 256 \\
\hline BUS-0019 & 480 & -1.4 & 13.71 & 7.48 & 281 & 239 & 256 \\
\hline BUS-0024 & 480 & -1.4 & 13.71 & 7.48 & 281 & 239 & 256 \\
\hline BUS-0025 & 480 & -1.4 & 13.7 & 7.48 & 281 & 239 & 256 \\
\hline BUS-0029 & 480 & -1.61 & 13.45 & 7.25 & 282 & 240 & 257 \\
\hline BUS-0039 & 480 & -2.03 & 12.96 & 6.79 & 283 & 241 & 258 \\
\hline
\end{tabular}

Table 2 shows that the voltage drop percentages vary depending on the Phase. The next category that was studied during the load flow analysis was the conductors. Table 3 lists the results found, but as with the previous table, due to the size of this table, the table below only shows a sample of the results; the complete table has been supplied in Appendix C, 9.2.

Table 3. Load-flow conductor information.

\begin{tabular}{|c|c|c|c|c|c|c|c|c|}
\hline BRANCH NAME & FROM NAME & TO NAME & TYPE & Phase & VD\% & AMPS & KVA & RATING\% \\
\hline \multirow[t]{3}{*}{ Utility Underground } & BUS-0001 & BUS-0002 & FDR & $(\mathrm{A})$ & 0.02 & 72.47 & 516.38 & 48.32 \\
\hline & & & & (B) & 0.03 & 84.5 & 601.1 & 56.34 \\
\hline & & & & (C) & 0.02 & 79.55 & 565.33 & 53.03 \\
\hline \multirow[t]{3}{*}{ Utility Supplied } & BUS-0002 & BUS-0039 & TX3 & (A) & 3.09 & 72.47 & 516.25 & 90.74 \\
\hline & & & & (B) & 11.73 & 84.5 & 600.93 & 105.81 \\
\hline & & & & (C) & 5.48 & 79.55 & 565.2 & 99.6 \\
\hline \multirow[t]{3}{*}{ MCC1 Feeder Cable } & QED MAIN SWITCHGEAR & MCC1/QED SB BUS & FDR & (A) & 0.3 & 566.76 & 160.18 & 40.2 \\
\hline & & & & (B) & 0.35 & 660.23 & 159.14 & 46.82 \\
\hline & & & & (C) & 0.33 & 621.88 & 160.53 & 44.1 \\
\hline \multirow[t]{3}{*}{ MCC2 Feeder Cable } & QED MAIN SWITCHGEAR & MCC2/QED SB BUS & FDR & (A) & 0.32 & 400.02 & 113.05 & 42.55 \\
\hline & & & & (B) & 0.36 & 460.68 & 111.04 & 49.01 \\
\hline & & & & (C) & 0.36 & 443.06 & 114.37 & 47.13 \\
\hline \multirow[t]{3}{*}{ Dryer Feeder Cable } & QED MAIN SWITCHGEAR & Dryer Control & FDR & (A) & 0.55 & 146.58 & 41.42 & 63.73 \\
\hline & & & & (B) & 0.65 & 172.32 & 41.54 & 74.92 \\
\hline & & & & (C) & 0.6 & 160.69 & 41.48 & 69.87 \\
\hline \multirow[t]{3}{*}{ MCC4 Feeder Cable } & QED MAIN SWITCHGEAR & MCC4/QED SB BUS & FDR & (A) & 0.41 & 769.43 & 217.45 & 54.57 \\
\hline & & & & (B) & 0.49 & 902.15 & 217.45 & 63.98 \\
\hline & & & & (C) & 0.45 & 841.01 & 217.1 & 59.65 \\
\hline \multirow[t]{3}{*}{ Main Feeder Cable } & BUS-0039 & QED MAIN SWITCHGEAR & FDR & (A) & 0.06 & 1882.78 & 532.4 & 66.06 \\
\hline & & & & (B) & 0.07 & 2195.35 & 529.57 & 77.03 \\
\hline & & & & (C) & 0.06 & 2066.62 & 533.84 & 72.51 \\
\hline
\end{tabular}

In the tables above, note the amperes and rating percentage of the cables and the transformers. The utility-supplied transformer, as well as other conductors in the complete table in Appendix C, 9.2 and the equipment report in Appendix F, show ampacity ratings higher than the $100 \%$ capability of the conductor (also shown below in Table 4). 
Table 4. Failed equipment report.

\begin{tabular}{|c|c|c|c|c|c|c|c|c|c|c|c|}
\hline & A & B & $\mathrm{C}$ & $\mathrm{D}$ & $E$ & $\mathrm{~F}$ & $\mathrm{G}$ & $\mathrm{H}$ & 1 & $\mathrm{~J}$ & $\mathrm{~K}$ \\
\hline 1 & Device & Status & Bus & Bus & Rated & VD\% & LF & Design & Ampacity & LF\% & Design $\%$ \\
\hline 2 & & & & Volts & Volts & & Amps & Amps & & & \\
\hline 3 & MCC1 CBL21 & Fail & IVMCC BUS & 480 & 600 & 0.26 & $\approx 259.23$ & ×301.51 & 230.0 & $\times 112.71$ & :131.09 \\
\hline 4 & MCC1 CBL22 & Fail & VMCC BUS & 480 & 600 & 0.26 & «259.23 & *301.51 & 230.0 & *112.71 & *131.09 \\
\hline 5 & MCC1 CBL5 & Fail & MCC1/QED SB BUS & 480 & 600 & 0.17 & *520.40 & *544.53 & 380.0 & *136.95 & *143.30 \\
\hline 6 & MCC2 CBL27 & Fail & MCC2A BUS & 480 & 600 & 0.73 & ${ }^{*} 65.07$ & ${ }^{\star} 75.38$ & 50.0 & *130.14 & *150.76 \\
\hline 7 & & & & & & & & & & & \\
\hline 8 & MCC4 CBL48 & Fail & MCC4A BUS & 480 & 600 & 0.25 & *324.01 & *376.89 & 310.0 & *104.52 & *121.58 \\
\hline 9 & MCC4 CBL5 & Fail & MCC4/QED SB BUS & 480 & 600 & 0.06 & *431.36 & *476.99 & 380.0 & *113.52 & *125.52 \\
\hline 10 & MCC4 CBL50 & Fail & MCC4B BUS & 480 & 600 & 0.25 & *324.04 & *376.89 & 310.0 & *104.53 & *121.58 \\
\hline 11 & MCC4 CBL6 & Fail & MCC4/QED SB BUS & 480 & 600 & 0.06 & 332.18 & *384.42 & 380.0 & 87.42 & *101.16 \\
\hline 12 & & & & & & & & & & & \\
\hline 13 & \begin{tabular}{|l|} 
MCC1 Dist Xfrmr1 (Pri) \\
\end{tabular} & Fail *(P,S) & MCC1 BUS & 480 & ${ }^{*} 480$ & *3.70 & *14.92 & ${ }^{*} 11.25$ & 10.8 & *137.83 & *103.90 \\
\hline 14 & MCC2 Dist Xfrmr0 (Pri) & Fail * $(P, S)$ & MCC2B BUS & 480 & ${ }^{*} 480$ & ${ }^{*} 6.62$ & *27.79 & *21.46 & 10.8 & *256.69 & *198.24 \\
\hline 15 & Utility Supplied XFMR (Pr & Fail ${ }^{*}(\mathrm{P}, \mathrm{S})$ & BUS-0002 & 12470 & 12470 & *4.91 & ${ }^{*} 79.14$ & ${ }^{\star} 76.31$ & 79.9 & ${ }^{*} 99.09$ & ${ }^{*} 95.55$ \\
\hline
\end{tabular}

The load flow currents are used to monitor the ampacity rating limits of the cables to be sure that the sizing of each conductor was properly done. It can be seen clearly in Table 6 above which conductors have the potential of being overloaded. Recommendations:

- Both MCC1 CBL21 \& MCC1 CBL22 have a design ampacity value of 301.51amps and a 4/0 AWG cable rated at 230 amps. Consider upsizing these cables to a $350 \mathrm{kcmil}$ size cable rated at 310 amps.

- $\quad$ MCC1 CBL5 has a design ampacity value of 544.53 amps and a $500 \mathrm{kcmil}$ cable rated at 380 amps. Consider upsizing this cable to a $1000 \mathrm{kcmil}$ size cable rated at 545 amps.

- MCC2 CBL27 has a design ampacity value of 75.38 amps and an 8 AWG cable rated at 50 amps. Consider upsizing this cable to a $4 / 0$ AWG size cable rated at 85 amps.

- Both MCC4 CBL48 \& MCC4 CBL50 have a design ampacity value of 376.89 amps and a $350 \mathrm{kcmil}$ cable rated at 310 amps. Consider upsizing these cables to a $500 \mathrm{kcmil}$ size cable rated at 380 amps.

- $\quad$ MCC4 CBL5 has a design ampacity value of 476.99 amps and a $500 \mathrm{kcmil}$ cable rated at 380 amps. Consider upsizing this cable to an $800 \mathrm{kcmil}$ size cable rated at 490 amps.

- MCC1 Xfrmr1 has a design ampacity value of 11.25 amps and an ampacity rating of 10.8 amps. Consider upsizing this transformer to a $15 \mathrm{KVA}$ size rated for 18 amps.

- MCC2 Xfrmr0* has a design ampacity value of 21.46 amps and an ampacity rating of 10.8 amps. Consider upsizing this transformer to a $22.5 \mathrm{KVA}$ size rated for 27 amps. *Note: It has been determined that the current cabinet this transformer is located in can only support up to a $15 \mathrm{KVA}$ transformer. A $22.5 \mathrm{KVA}$ transformer would require a new cabinet. The control trailer load (approximately 30 amps) is the major load on this transformer and not connected or at full load at all times, thus a $15 \mathrm{KVA}$ transformer would suffice for the other loads and it is believed that a $15 \mathrm{KVA}$ transformer would support the control trailer load but would have a reduced life because of the overloading occurred during the control trailer loading. 
Table 5, Table 6, and Table 7 show the load-flow results for the transformer, the utility, the loads, and the motors within the system. Note: again due to size, Table 6 and Table 7 are sample tables, with the complete set of results located in Appendix A, 7.4 and 7.5). Power, both real and reactive (kW and kVAR) have been shown, as well as percent voltage drop and load flow current (A).

Table 5. Load-flow transformer (XFRMR) and utility information.

\begin{tabular}{l|l|r|r|r} 
2-Winding Transformer & Phase & $(\mathrm{kW})$ & (kVAR) & PctVD(\%) \\
\hline Utility Supplied XFRMR & A: & 426.3 & 318.9 & 3.09 \\
\hline & B: & 423.9 & 317.4 & 11.73 \\
\hline & C: & 425.5 & 322.4 & 5.48 \\
\hline MCC1 Dist XFRMR & A: & 1.9 & 1.4 & 5.26 \\
\hline & B: & 1.6 & 1.2 & 2.69 \\
\hline & C: & 3.2 & 2.3 & 0.39 \\
\hline MCC2 Dist XFRMR & A: & 4.1 & 3.1 & 7.79 \\
\hline & B: & 1.7 & 1.2 & 2.81 \\
\hline & C: & 5.5 & 4 & 2.42 \\
\hline MCC4 Dist XFRMR & A: & 1.8 & 1.3 & 5.1 \\
\hline & B: & 1.6 & 1.2 & 2.65 \\
\hline & C: & 1.6 & 1.2 & 2.24 \\
& & & & \\
Utility & Phase & $(\mathrm{kW})$ & (kVAR) & PctVD(\%) \\
\hline Utility & A & 411.19 & 312.35 & 1.03 \\
\hline & B & 481.34 & 360.05 & 1.2 \\
\hline & C & 403.1 & 396.38 & 1.29
\end{tabular}


Table 6. Load-flow general load information.

\begin{tabular}{|c|c|c|c|c|c|}
\hline General Load & Phase & $(\mathrm{kW})$ & (kVAR) & PctVD(\%) & LF Current $(\mathrm{A})$ \\
\hline \multirow[t]{3}{*}{ Leveling Jacks } & A: & 3.5 & 2.7 & 0.17 & $\begin{array}{r}15.8 \\
\end{array}$ \\
\hline & B: & 3.5 & 2.7 & 0.2 & 18.5 \\
\hline & C: & 3.5 & 2.7 & 0.19 & 17.3 \\
\hline \multirow[t]{3}{*}{ Metering Bin MC } & A: & 17.7 & 13.3 & 0.16 & 78.8 \\
\hline & B: & 17.7 & 13.3 & 0.19 & 92.6 \\
\hline & C: & 17.7 & 13.3 & 0.18 & 86.4 \\
\hline \multirow[t]{3}{*}{ Screw Conveyor Control SC-4 } & A: & 3.5 & 2.7 & 0.17 & 15.8 \\
\hline & B: & 3.5 & 2.7 & 0.2 & 18.5 \\
\hline & C: & 3.5 & 2.7 & 0.19 & 17.3 \\
\hline \multirow[t]{3}{*}{ Screw Conveyor Control SC-5 } & A: & 3.5 & 2.7 & 0.17 & 15.8 \\
\hline & B: & 3.5 & 2.7 & 0.2 & 18.5 \\
\hline & C: & 3.5 & 2.7 & 0.19 & 17.3 \\
\hline \multirow[t]{3}{*}{ Screw Conveyor Control SC-6 } & A: & 3.5 & 2.7 & 0.17 & 15.8 \\
\hline & B: & 3.5 & 2.7 & 0.2 & 18.5 \\
\hline & C: & 3.5 & 2.7 & 0.19 & 17.3 \\
\hline \multirow[t]{3}{*}{ Densification Module Heaters } & A: & 3.5 & 2.7 & 0.17 & 15.8 \\
\hline & B: & 3.5 & 2.7 & 0.2 & 18.5 \\
\hline & C: & 3.5 & 2.7 & 0.19 & 17.3 \\
\hline \multirow[t]{3}{*}{ MCC4 Bard A/C Unit } & A: & 3 & 2.3 & 0.17 & 13.4 \\
\hline & B: & 3 & 2.3 & 0.2 & 15.8 \\
\hline & C: & 3 & 2.3 & 0.18 & 14.7 \\
\hline \multirow[t]{3}{*}{ MCC1 Bard A/C Unit } & A: & 3.1 & 2.3 & 0.18 & 13.8 \\
\hline & B: & 2.3 & 1.7 & 0.14 & 11.8 \\
\hline & C: & 2.6 & 1.9 & 0.15 & 12.6 \\
\hline \multirow[t]{3}{*}{ MCC2 Bard A/C Unit } & A: & 2.4 & 1.8 & 0.21 & 10.6 \\
\hline & B: & 2.4 & 1.8 & 0.25 & 12.5 \\
\hline & C: & 2.4 & 1.8 & 0.23 & 11.7 \\
\hline
\end{tabular}


Table 7. Load-flow induction motor information.

\begin{tabular}{|c|c|c|c|c|c|c|}
\hline Induction Motor & Phase & $(\mathrm{kW})$ & (kVAR) & PctVD(\%) & LF Current (A) & (hp) \\
\hline \multirow[t]{3}{*}{ Bucket Elevator OBE-2 } & A: & \begin{tabular}{|l|}
0.4 \\
\end{tabular} & \begin{tabular}{|l|}
0.3 \\
\end{tabular} & 0.02 & 1.8 & 1.5 \\
\hline & B: & 0.4 & 0.3 & 0.02 & 2.1 & \\
\hline & C: & 0.4 & 0.3 & 0.02 & 2 & \\
\hline \multirow[t]{3}{*}{ Drag Conveyor DC-7 } & A: & 1.3 & 1 & 0.06 & 5.9 & 5 \\
\hline & B: & 1.3 & 1 & 0.08 & 7 & \\
\hline & C: & 1.3 & 1 & 0.07 & 6.5 & \\
\hline \multirow[t]{3}{*}{ Belt Conveyor BC-1 } & A: & 0.5 & 0.4 & 0.03 & 2.4 & 2 \\
\hline & B: & 0.5 & 0.4 & 0.03 & 2.8 & \\
\hline & C: & 0.5 & 0.4 & 0.03 & 2.6 & \\
\hline \multirow[t]{3}{*}{ Drag Conveyor DC-8 } & $\mathrm{A}:$ & 1.3 & 1 & 0.06 & 5.9 & 5 \\
\hline & B: & 1.3 & 1 & 0.08 & 7 & \\
\hline & C: & 1.3 & 1 & 0.07 & 6.5 & \\
\hline \multirow[t]{3}{*}{ Drag Conveyor DC-6 } & $\mathrm{A}:$ & 1.3 & 1 & 0.06 & 5.9 & 5 \\
\hline & B: & 1.3 & 1 & 0.08 & 7 & \\
\hline & C: & 1.3 & 1 & 0.07 & 6.5 & \\
\hline \multirow[t]{3}{*}{ Drag Conveyor DC-9 } & A: & 1.3 & 1 & 0.06 & 5.9 & 5 \\
\hline & B: & 1.3 & 1 & 0.08 & 7 & \\
\hline & C: & \begin{tabular}{l|l}
1.3 \\
\end{tabular} & 1 & 0.07 & 6.5 & \\
\hline \multirow[t]{3}{*}{ Inlet Airlock } & A: & 0.5 & 0.3 & 0.03 & 2 & 1.5 \\
\hline & B: & 0.5 & 0.3 & 0.04 & 2.4 & \\
\hline & C: & 0.5 & 0.3 & 0.04 & 2.2 & \\
\hline \multirow[t]{3}{*}{ Outlet Airlock } & A: & 0.6 & 0.4 & 0.04 & 2.6 & 1.5 \\
\hline & B: & 0.6 & 0.4 & 0.05 & 3 & \\
\hline & C: & 0.6 & 0.4 & 0.05 & 2.8 & \\
\hline
\end{tabular}

\subsection{Protective Device Coordination}

The protective device coordination study was performed in order to determine whether the breakers and fuses were properly sized, with settings appropriately set in order to protect the system. It is ideal to have the protective device interrupt only the section of the system that has the fault; when this is achieved as best as possible, the system is said to be coordinated. The device furthest from the utility was selected as the starting point for the coordination study. Working back towards the utility, the protective device coordination resulted in the following settings (samples shown below in Table 8 and Table 9, with complete tables found in Appendix A, 7.6 and 7.7) for each of the breakers and fuses on the system. 
Table 8. Protective-device coordination breaker settings.

\begin{tabular}{|c|c|c|c|c|}
\hline LV Breakers & Decorintion & $T=0$ & Frrmos concor/Plun & SETTINCS \\
\hline \multirow{7}{*}{ Main SwitchGear } & & & & \\
\hline & SQUARE D & RK & $2500.0 \mathrm{~A}$ & LTPU/LTD (A 0.4-1.0 x S) 1 (2500A); 0.5 \\
\hline & Powerpact R-Frame, 6.0A/P/H & & $2500.0 \mathrm{~A}$ & STPU (1.5-10 x LTPU) 5 (12500A) \\
\hline & LSI, 600-2500A, UL & & & STD $(0-0.4) 0.1$ (|^2t Out) \\
\hline & SQUARE D & RK & $2500.0 \mathrm{~A}$ & INST $(2-15 \times$ S $) 6(15000 A)$ \\
\hline & Powerpact R-Frame, 6.0A/P/H & & $2500.0 \mathrm{~A}$ & GFPU (500-1200A) J (1200A) \\
\hline & GF, 1600-2500AS, UL & & & GFD $(0-0.4) 0.4\left(I^{\wedge} 2 \mathrm{t} \ln \right)$ \\
\hline \multirow[t]{6}{*}{ Main SGB1 } & SQUARE D & PJ & $1200.0 \mathrm{~A}$ & LTPU/LTD (A 0.4-1.0 x S) 0.9 (900A); 1 \\
\hline & Powerpact P-Frame, 6.0A/P/H & & $1000.0 \mathrm{~A}$ & STPU (1.5-10 x LTPU) 10 (9000A) \\
\hline & LSI, 100-1200A, UL & & & $\operatorname{STD}(0-0.4) 0.4\left(I^{\wedge} 2 \mathrm{t} \mathrm{In}\right)$ \\
\hline & SQUARE D & PK & $1200.0 \mathrm{~A}$ & INST $(2-15 \times \mathrm{S}) 6(6000 \mathrm{~A})$ \\
\hline & Powerpact P-Frame, 6.0A/P/H & & $600.0 \mathrm{~A}$ & GFPU $(0.2-1.0 \times \mathrm{S}) \mathrm{D}(300 \mathrm{~A})$ \\
\hline & GF, 600-1200AS, UL & & & GFD $(0-0.4) 0.2\left(I^{\wedge} 2 t \ln \right)$ \\
\hline \multirow[t]{6}{*}{ Main SGB2 } & SQUARE D & PJ & $1200.0 \mathrm{~A}$ & LTPU/LTD (A 0.4-1.0 x S) $0.9(900 \mathrm{~A}) ; 1$ \\
\hline & Powerpact P-Frame, 6.0A/P/H & & $1000.0 \mathrm{~A}$ & STPU (1.5-10 x LTPU) 10 (9000A) \\
\hline & LSI, 100-1200A, UL & & & STD $(0-0.4) 0.4\left(I^{\wedge} 2 \mathrm{t}\right.$ In) \\
\hline & SQUARE D & PK & $1200.0 \mathrm{~A}$ & INST $(2-15 \times \mathrm{S}) 6(6000 \mathrm{~A})$ \\
\hline & Powerpact P-Frame, 6.0A/P/H & & $600.0 \mathrm{~A}$ & GFPU $(0.2-1.0 \times S) D(300 A)$ \\
\hline & GF, 600-1200AS, UL & & & GFD $(0-0.4) 0.2\left(1^{\wedge} 2 \mathrm{t} \ln \right)$ \\
\hline \multirow[t]{6}{*}{ Main SGB3 } & SQUARE D & PJ & $1200.0 \mathrm{~A}$ & LTPU/LTD (A 0.4-1.0 x S) $0.9(900 \mathrm{~A}) ; 1$ \\
\hline & Powerpact P-Frame, 6.0A/P/H & & $1000.0 \mathrm{~A}$ & STPU (1.5-10 x LTPU) 10 (9000A) \\
\hline & LSI, 100-1200A, UL & & & STD $(0-0.4) 0.4\left(\left.\right|^{\wedge} 2 \mathrm{t} \ln \right)$ \\
\hline & SQUARE D & PK & $1200.0 \mathrm{~A}$ & INST $(2-15 \times$ S $) 6(6000 \mathrm{~A})$ \\
\hline & Powerpact P-Frame, 6.0A/P/H & & $600.0 \mathrm{~A}$ & GFPU $(0.2-1.0 \times \mathrm{S}) \mathrm{D}(300 \mathrm{~A})$ \\
\hline & GF, 600-1200AS, UL & & & GFD $(0-0.4) 0.2\left(I^{\wedge} 2 t \ln \right)$ \\
\hline \multirow[t]{6}{*}{ Main SGB4 } & SQUARE D & PJ & $1200.0 \mathrm{~A}$ & LTPU/LTD (A 0.4-1.0 x S) $0.9(900 \mathrm{~A}) ; 1$ \\
\hline & Powerpact P-Frame, 6.0A/P/H & & $1000.0 \mathrm{~A}$ & STPU (1.5-10 x LTPU) 10 (9000A) \\
\hline & LSI, 100-1200A, UL & & & STD (0-0.4) $0.4\left(\left(^{\wedge} 2 \mathrm{t} \ln \right)\right.$ \\
\hline & SQUARE D & PK & $1200.0 \mathrm{~A}$ & INST $(2-15 \times$ S $) 6(6000 \mathrm{~A})$ \\
\hline & Powerpact P-Frame, 6.0A/P/H & & $600.0 \mathrm{~A}$ & GFPU $(0.2-1.0 \times \mathrm{S}) \mathrm{D}(300 \mathrm{~A})$ \\
\hline & GF, 600-1200AS, UL & & & GFD $(0-0.4) 0.2\left(\left(^{\wedge} 2 \mathrm{t} \ln \right)\right.$ \\
\hline
\end{tabular}


Table 9. Protective-device coordination fuse settings.

\begin{tabular}{|c|c|c|c|}
\hline Fuses & Description & FRAME/MODEL & Cartridge/Trip \\
\hline \multirow[t]{3}{*}{ Utility Fuse } & SQUARE D & CS-3, 100E & $100.0 \mathrm{~A}$ \\
\hline & CS-3, 15.5kV E-Rated & & $100.0 \mathrm{~A}$ \\
\hline & $10 \mathrm{E}-100 \mathrm{E}$ & & \\
\hline \multirow[t]{3}{*}{ MCC1 Fuse 1} & BUSSMANN & JKS & $30.0 \mathrm{~A}$ \\
\hline & JKS, 600V Class J & & $30.0 \mathrm{~A}$ \\
\hline & $1-600 \mathrm{~A}$ & & \\
\hline \multirow[t]{3}{*}{ MCC1 Fuse 2} & BUSSMANN & JKS & $30.0 \mathrm{~A}$ \\
\hline & JKS, 600V Class J & & $30.0 \mathrm{~A}$ \\
\hline & $1-600 \mathrm{~A}$ & & \\
\hline \multirow[t]{3}{*}{ MCC1 Fuse 3} & BUSSMANN & JKS & $30.0 \mathrm{~A}$ \\
\hline & JKS, 600V Class J & & $30.0 \mathrm{~A}$ \\
\hline & $1-600 \mathrm{~A}$ & & \\
\hline \multirow[t]{3}{*}{ MCC1 Fuse 4} & BUSSMANN & JKS & $100.0 \mathrm{~A}$ \\
\hline & JKS, 600V Class J & & $100.0 \mathrm{~A}$ \\
\hline & $1-600 \mathrm{~A}$ & & \\
\hline \multirow[t]{3}{*}{ MCC1 Fuse 5} & BUSSMANN & JKS & $400.0 \mathrm{~A}$ \\
\hline & JKS, 600V Class J & & $400.0 \mathrm{~A}$ \\
\hline & $1-600 \mathrm{~A}$ & & \\
\hline \multirow[t]{3}{*}{ MCC1 Fuse 6} & BUSSMANN & JKS & $400.0 \mathrm{~A}$ \\
\hline & JKS, 600V Class J & & $400.0 \mathrm{~A}$ \\
\hline & $1-600 \mathrm{~A}$ & & \\
\hline \multirow[t]{3}{*}{ MCC1 Fuse 7} & BUSSMANN & JKS & $30.0 \mathrm{~A}$ \\
\hline & JKS, 600V Class J & & $30.0 \mathrm{~A}$ \\
\hline & $1-600 \mathrm{~A}$ & & \\
\hline \multirow[t]{3}{*}{ MCC1 Fuse 8} & BUSSMANN & JKS & $30.0 \mathrm{~A}$ \\
\hline & JKS, 600V Class J & & $30.0 \mathrm{~A}$ \\
\hline & $1-600 \mathrm{~A}$ & & \\
\hline \multirow[t]{3}{*}{ MCC1 Fuse 9} & BUSSMANN & JKS & $100.0 \mathrm{~A}$ \\
\hline & JKS, 600V Class J & & $100.0 \mathrm{~A}$ \\
\hline & 1-600A & & \\
\hline \multirow[t]{3}{*}{ MCC1 PTS Fuse 1} & BUSSMANN & LPJ-60SP & $60.0 \mathrm{~A}$ \\
\hline & LPJ_SP, 600V Class J & & $60.0 \mathrm{~A}$ \\
\hline & $15-600 \mathrm{~A}$ & & \\
\hline \multirow[t]{3}{*}{ MCC1 PTS Fuse 2} & BUSSMANN & LPJ-30SP & $30.0 \mathrm{~A}$ \\
\hline & LPJ_SP, 600V Class J & & $30.0 \mathrm{~A}$ \\
\hline & $15-600 A$ & & \\
\hline
\end{tabular}

As part of the protective device coordination, the Computer Aided Plotting for Time Overcurrent Reporting (CAPTOR) study module was used to plot the TCC characteristics of the electrical components to ensure that they protect the various different electrical apparatus from possible overload and shortcircuit currents. As part of the study, the locked rotor starting curves were placed on a log-log grid as were the thermal and mechanical damage curves for cables and transformers. Each protective device was then plotted, showing its TCC curve based upon the manufacturer's specifications that were loaded in from the device library.

The following TCC drawing (Figure 3) represents the worst-case path from the largest motor load back to the utility and all of the electrical protection devices in between. Other TCC drawings can be seen in Appendix D. 


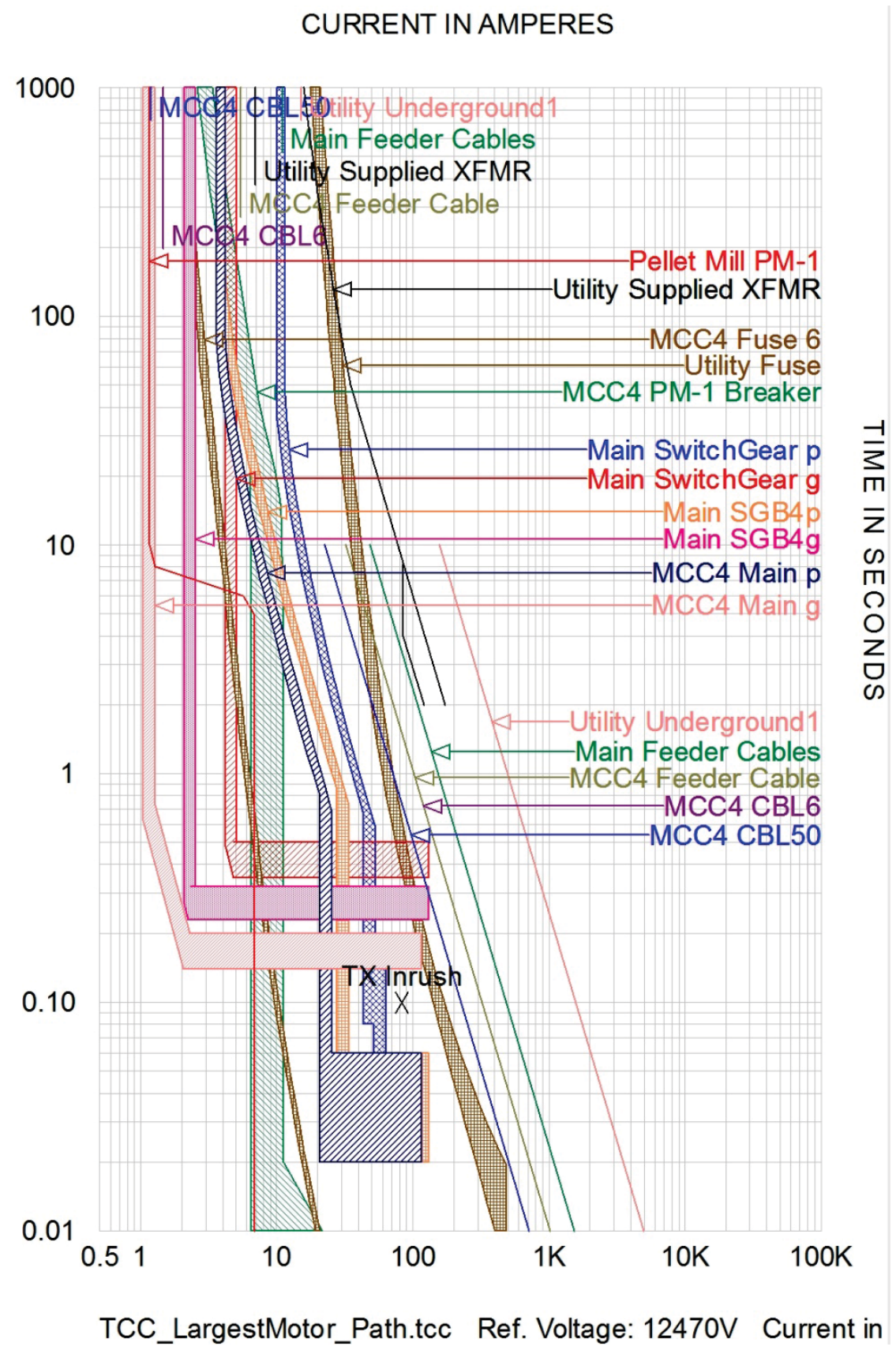

Figure 3. Largest motor TCC drawing for protective-device coordination study.

As shown in the TCC drawing, the coordination of the upstream protective devices is to limit the extent and duration of service interruption during an equipment failure or any other failure on the system. Reducing the amount of damage caused to the system components during such failures is also an objective of the protective-device coordination study. These failures are usually unpredictable, but good engineering design and judgment can reduce the adverse affects that the system can endure.

This system has been protected in concert with the functionality of the electrical components and the safety of the equipment and personnel working in the area. Coordination has been done to isolate the area of abnormality and not to interrupt the performance and operation of the rest of the system. However, 
Table 10 shows that a possibility for failure exists for breakers MCC1 DC-5, MCC4 AL-2, MCC4 CRF-1, MCC4 DC-1, MCC4 PM-2, MCC4 PMC-1, and MCC4 SC-3.

Table 10. Breaker failure report.

\begin{tabular}{|c|c|c|c|c|c|c|c|}
\hline & A & $\mathrm{B}$ & $\mathrm{C}$ & $\mathrm{D}$ & $\mathrm{E}$ & $\mathrm{F}$ & G \\
\hline 1 & Device/Bus & Status & Description & Voltage (V) & Continuous Amps & INT kA & Rating\% \\
\hline 2 & Manufacturer & & & Bus/Device & LF/Dev/Rating\% & Calc/Dev/Series & Volt/INT \\
\hline 3 & MCC1 DC-5 Breaker & Fail & Powerpact HJ & 480 & 2.58 & 28.50 & 80.00 \\
\hline 4 & MCC1 BUS & & $15-150 \mathrm{~A}$ & 600 & 30.00 & 25.00 & "113.98 \\
\hline 5 & SQUARE D & & $\mathrm{HJ}$ & & 8.60 & & \\
\hline 7 & MCC4 AL-2 Breaker & Fail & Powerpact HJ & 480 & 2.58 & 29.39 & 80.00 \\
\hline 8 & MCCAA BUS & & $15-150 \mathrm{~A}$ & 600 & 30.00 & 25.00 & "117.57 \\
\hline 9 & SQUARE D & & HJ & & 8.61 & & \\
\hline 11 & MCC4 CRF-1 Breaker & Fail & Powerpact HJ & 480 & 1.29 & 29.39 & 80.00 \\
\hline 12 & MCC4A BUS & & $15-150 A$ & 600 & 30.00 & 25.00 & "117.57 \\
\hline 13 & SQUARE D & & $\mathrm{HJ}$ & & 4.31 & & \\
\hline 15 & MCC4 DC-1 Breaker & Fail & Powerpact HJ & 480 & 6.46 & 29.39 & 80.00 \\
\hline 16 & MCCAA BUS & & $15-150 \mathrm{~A}$ & 600 & 30.00 & 25.00 & "117.57 \\
\hline 17 & SQUARE D & & $\mathrm{HJ}$ & & 21.54 & & \\
\hline 19 & MCC4 PM-2 Breaker & Fail & LAL Mag-Gard & 480 & 323.74 & "29.39 & 80.00 \\
\hline 20 & MCC4A BUS & & $400 \mathrm{~A}$ & 600 & 400.00 & 22.00 & ${ }^{*} 133.61$ \\
\hline 21 & SQUARE D & & LAL & & 80.93 & & \\
\hline 23 & MCC4 PMC-1 Breaker & Fail & Powerpact HJ & 480 & 12.92 & 29.39 & 80.00 \\
\hline 24 & MCC4A BUS & & 15-150A & 600 & 30.00 & 25.00 & *117.57 \\
\hline 25 & SQUARE D & & $\mathrm{HJ}$ & & 43.07 & & \\
\hline 27 & MCC4 SC-3 Breaker & Fail & Powerpact HJ & 480 & 6.46 & 29.39 & 80.00 \\
\hline 28 & MCCAA BUS & & $15-150 A$ & 600 & 30.00 & 25.00 & "117.57 \\
\hline 29 & SQUARE D & & $\mathrm{HJ}$ & & 21.53 & & \\
\hline
\end{tabular}

\subsection{Arc Flash Hazard Analysis}

An arc-flash analysis has been performed on the BioMass PDU electrical system to help provide safety guidance to reduce or prevent injury to workers. The arc flash analysis also provides workers with the appropriate personal protective equipment (PPE), detailed system modeling and, most importantly, the ability to better protect against loss of life.

The following information regarding the arc flash analysis does not guarantee full protection; it is always suggested to de-energize equipment before performing maintenance. However, this is not always an option, and the following results should aid in the protection of the workers involved. There are a few definitions regarding the information listed within the arc-flash analysis results that need to be described. All definitions have been taken from the SKM Power Tools for Windows Arc Flash Evaluation Study Manager.

- Bus Name: Fault location for bus report. For line side and load side report options the bus refers to the equipment where the line side and load side protective devices are connected.

- Protective Device Name: Refers to the protective device that clears the arcing fault or portion of the total arcing fault current.

- Bus kV: Bus voltage at the fault location. 
- Bus Bolted Fault Current (kA): The current flowing to a bus fault that occurs between two or more conductors or bus bars, where the impedance between the conductors is zero.

- Bus Arcing Fault: The calculated arcing current on the faulted bus

- Protective Device Bolted Fault Current (kA): The portion of the total bolted fault current that flows through a given protective device.

- Protective Device Arcing Fault Current (kA): The arc current flowing through each protective device feeding the electric arc fault. Note that the total arc fault current may flow through several parallel sources to the arc location.

- Trip/Delay Time: The time required for the protective device to operate for the given fault condition. In the case of a relay, the breaker opening time is entered separately from the relay trip time. For low voltage breakers and fuses, the trip time is assumed to be the total clearing curve or high tolerance of the published trip curve.

- Breaker Opening Time: The time required for a breaker to open after receiving a signal from the trip unit to operate. The combination of the Trip/Delay time and the Breaker Opening time determines the total time required to clear the fault. For low-voltage circuit breakers, the total clearing time displayed on the Manufacturer's drawing is assumed to include the breaker opening time.

- Ground: Indicates whether the fault location includes a path to ground. Systems with high-resistance grounds are assumed to be ungrounded in the Arc Flash calculations. (Available for IEEE 1584 only)

- Equip Type: Used only in the IEEE 1584 method to indicate whether the equipment is Switchgear, Panel, Cable or Open Air. The equipment type provides a default Gap value and a distance exponent used in the IEEE incident energy equations. The equipment type provides a default Gap value and a distance exponent used in the IEEE incident energy equations.

- Gap: Used only in the IEEE 1584 method to define the spacing between bus bars or conductors at the arc location.

- Duration of Arc: The summation of Trip/Delay Time and Breaker Opening Time.

- Arc Type: Identifies whether the fault location is in an enclosure or in open air. In open air the arc energy will radiate in all directions whereas an enclosure will focus the energy toward the enclosure opening. The In Box / Air selection is available when the NFPA 70E study option is selected. For the IEEE 1584 study selection the In Box or In Air is determined automatically from the Equipment Type specification.

- Arc Flash Boundary: The distance from exposed live parts within which a person could receive a 2nd degree burn.

- Working Distance: The distance between the arc source and the worker's face or chest.

- Incident Energy: The amount of energy on a surface at a specific distance from a flash.

- Required Protective FR Clothing Category (PPE): Indicates the PPE required preventing an incurable burn at the working distance during an arcing fault.

- Label \#: This allows the user to specify the prefix character that will go on the "Label \#" column in the Arc Flash spreadsheet report. This field can help in sorting out (organizing) the label when they printed out.

- Cable Length from Trip Device: Reports the total cable length from the protective device that trips to clear the fault to the faulted bus. If there is no cable in between, nothing will be reported.

The results from the arc flash analysis show four main categories of concern. The first category is a Category 0 . This category incorporates most of the components within the system, and has an upper limit 
of $1.2 \mathrm{cal} / \mathrm{cm} 2$ for the incident energy. The proper clothing and equipment for this category, as well as all other categories, is described in the PPE Table on page 18. The second category is a Category 1, which has an incident energy range of $1.2-4 \mathrm{cal} / \mathrm{cm} 2$. The third category that shows up in the arc flash analysis report for this system is Category 2. Category 2 has an incident energy range of $4-8 \mathrm{cal} / \mathrm{cm} 2$. Categories $0-4$ require a Warning label with the appropriate arc flash information listed to be placed on the equipment. Finally, the last category that is present in this system is a category of Danger. This category is the most severe category, and requires a DANGER label to be placed on the equipment stating that live work is not to be performed. The incident energy range for the Danger category is $40-999 \mathrm{cal} / \mathrm{cm} 2$. 


\begin{tabular}{|c|c|c|c|c|c|c|}
\hline 熟 & 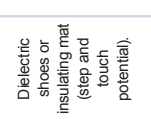 & 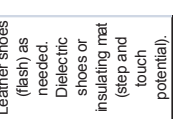 & 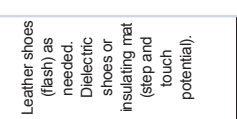 & 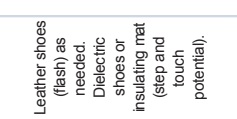 & 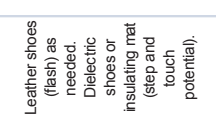 & 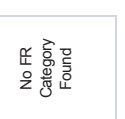 \\
\hline 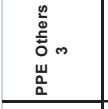 & 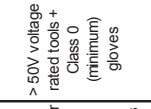 & 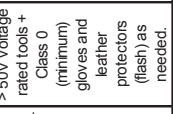 & 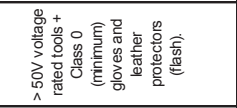 & 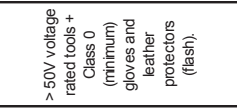 & 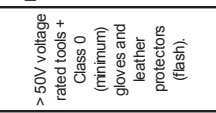 & 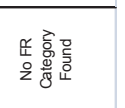 \\
\hline 然 & 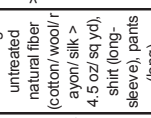 & 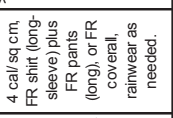 & 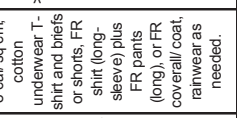 & 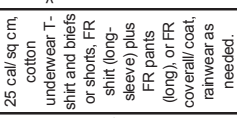 & 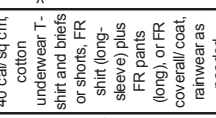 & 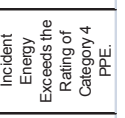 \\
\hline 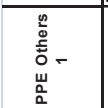 & & 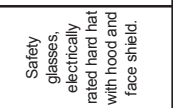 & 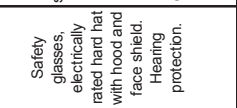 & 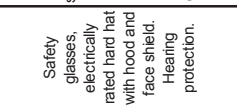 & 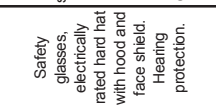 & 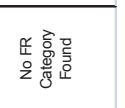 \\
\hline 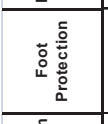 & 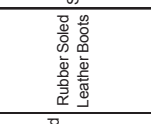 & 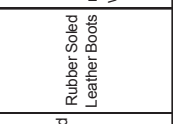 & 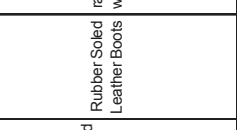 & 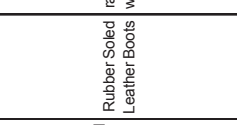 & 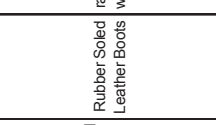 & 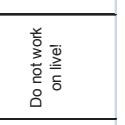 \\
\hline 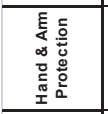 & 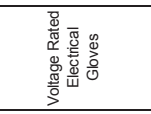 & 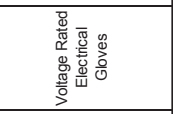 & 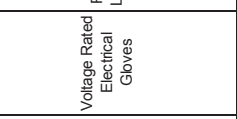 & 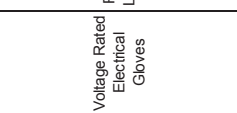 & 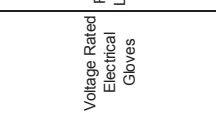 & 豪高 \\
\hline 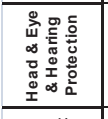 & 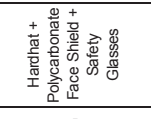 & 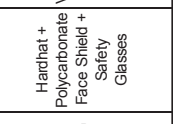 & 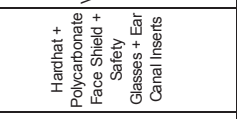 & 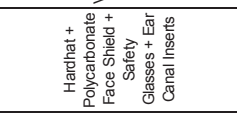 & 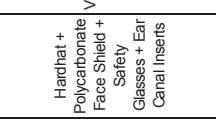 & 豪㝇 \\
\hline 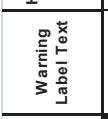 & 高 & $\frac{0}{\underline{2}}$ & 毫 & 亳 & 亳 & 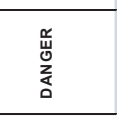 \\
\hline 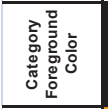 & & & & & & \\
\hline 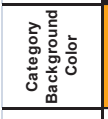 & & & & & & \\
\hline$\frac{\frac{2}{2}}{2}$ & & & & & & 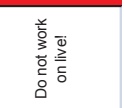 \\
\hline 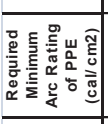 & $\frac{\pi}{z}$ & - & 。 & $:$ & $\because$ & $\frac{s}{z}$ \\
\hline 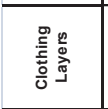 & - & - & ֻू & 咢 & 煦 & 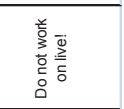 \\
\hline 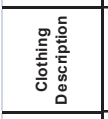 & 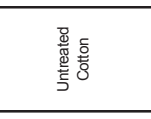 & 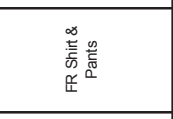 & 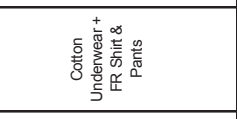 & 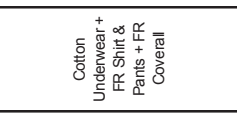 & 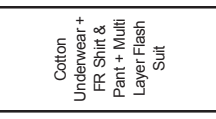 & 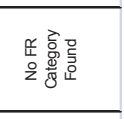 \\
\hline 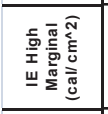 & 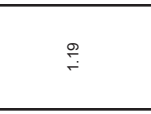 & $:$ & $\approx$ & $*$ & $\mathrm{~g}$ & $\mathrm{~g}$ \\
\hline 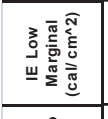 & 。 & $\bar{y}$ & $\bar{F}$ & z & $\approx$ & $\bar{F}$ \\
\hline 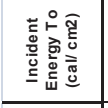 & $\cong$ & + & . & $\therefore$ & 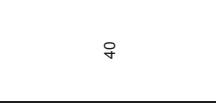 & $\stackrel{8}{8}$ \\
\hline 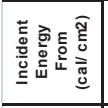 & 。 & $\cong$ & - & $\infty$ & : & 8 \\
\hline 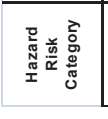 & 。 & - & $\sim$ & . & . & 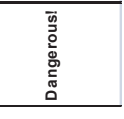 \\
\hline
\end{tabular}


Table 12. Arc-flash analysis results.

\begin{tabular}{|c|c|c|c|c|c|c|c|c|c|c|c|c|c|c|c|c|c|c|}
\hline Bus Name & $\left|\begin{array}{c}\text { Bus } \\
k \text { v }\end{array}\right|$ & \begin{tabular}{|c|} 
Bus \\
Bolted \\
Faut \\
{$[\mathrm{k} \boldsymbol{A})$} \\
\end{tabular} & $\begin{array}{l}\text { Bus } \\
\text { Arcing } \\
\text { Fault } \\
\text { [ke, } \\
\end{array}$ & 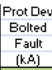 & 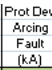 & $\begin{array}{l}\text { Tript } \\
\text { Delay } \\
\text { Time } \\
\text { (sec.) }\end{array} \mid$ & \begin{tabular}{|l} 
Bereaker \\
Opening \\
Time \\
[sec.j
\end{tabular} & Ground ${ }_{\text {G }}$ & $\begin{array}{l}\text { Equip } \\
\text { Type }\end{array}$ & $\begin{array}{l}\text { Gapp } \\
(m m)\end{array} \mid$ & $\begin{array}{l}\text { Arc } \\
\text { Flash } \\
\text { Boundary } \\
\text { (in] }\end{array}$ & \begin{tabular}{|l} 
Working \\
Distance \\
(in)
\end{tabular} & 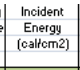 & $\left|\begin{array}{|c|}\text { Required Protective } \\
\text { FR Clothing Category }\end{array}\right|$ & Label \# & \begin{tabular}{|c|} 
Cable Length \\
From Trip Device \\
(ft) \\
\end{tabular} & 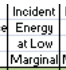 & \begin{tabular}{|}
$\mid$ Incident \\
Energy \\
ant High \\
Marginal
\end{tabular} \\
\hline EUS-0002 & 12.47 & \begin{tabular}{|l|l|}
4.89 \\
\end{tabular} & 4.80 & 4.61 & & & & \begin{tabular}{l|l} 
Yes & s
\end{tabular} & \begin{tabular}{|l|l|l|} 
SWG & 15 \\
\end{tabular} & 153 & 3 & 36 & 0.12 & Category 0 & \#0003 & & & \\
\hline BUS-0002 & 12.47 & 4.89 & 4.80 & 0.28 & 0.28 & 0.083 & 0.000 & \begin{tabular}{l|l} 
Yes & $\mathrm{s}$
\end{tabular} & \begin{tabular}{|l|l|} 
SWG & 15 \\
\end{tabular} & 153 & 3 & 36 & 0.14 & Category 0 & & 15.00 & & \\
\hline $\begin{array}{l}\text { MCC1BUS (Motor } \\
\text { Control Center 1) }\end{array}$ & 0.48 & 28.50 & 16.04 & 28.48 & 16.03 & 0.004 & 0.000 & No $\mathrm{F}$ & \begin{tabular}{|l|l|} 
PNL & 2
\end{tabular} & 25 & 8 & 18 & 0.30 & Category 0 & $\# 0046$ & 12.00 & & \\
\hline $\begin{array}{l}\text { MCCDEUS Motor } \\
\text { Control Center 1) }\end{array}$ & 0.48 & 28.50 & 16.04 & 0.01 & 0.01 & 0.083 & 0.000 & No $\mathrm{F}$ & \begin{tabular}{|l|l|} 
PNL & 2 \\
\end{tabular} & 25 & 8 & 18 & 0.30 & Category 0 & & & & \\
\hline $\begin{array}{l}\text { MCC2A BUS (Motor } \\
\text { Control Center 2A, }\end{array}$ & 0.48 & 24.99 & 14.34 & 24.55 & 14.08 & 0.004 & 0.000 & No $\mathrm{F}$ & \begin{tabular}{|l|l|} 
PNL & 2
\end{tabular} & 25 & 7 & 18 & 0.26 & Category 0 & \# 0047 & 20.00 & & \\
\hline $\begin{array}{l}\text { MCC2ABUS (Motor } \\
\text { Control Center 2A) }\end{array}$ & 0.48 & 24.99 & 14.34 & 0.01 & 0.01 & 0.083 & 0.000 & No $\mathrm{F}$ & \begin{tabular}{|l|l|} 
PNL & 2 \\
\end{tabular} & 25 & 9 & 18 & 0.39 & Category 0 & & & & \\
\hline $\begin{array}{l}\text { MCC2ABUS (Motor } \\
\text { Control Center 2A) }\end{array}$ & 0.48 & 24.99 & 14.34 & 0.02 & 0.01 & 0.083 & 0.000 & No $\mathrm{F}$ & \begin{tabular}{|l|l|} 
PNL & 2 \\
\end{tabular} & 25 & 9 & 18 & 0.39 & Category 0 & & & & \\
\hline $\begin{array}{l}\text { MCC2A BUS (Motor } \\
\text { Control Center 2A) }\end{array}$ & 0.48 & 24.99 & 14.34 & 0.35 & 0.20 & 0.083 & 0.000 & No $\mathrm{F}$ & \begin{tabular}{|l|l} 
PNL & 2 \\
\end{tabular} & 25 & 9 & 18 & 0.39 & Category 0 & & & & \\
\hline $\begin{array}{l}\text { MCC2ABUS (Motor } \\
\text { Control Center 2A) }\end{array}$ & 0.48 & 24.99 & 14.34 & 0.04 & 0.02 & 0.083 & 0.000 & No $\mathrm{F}$ & \begin{tabular}{|l|l|} 
PNL & 2
\end{tabular} & 25 & 9 & 18 & 0.39 & Category 0 & & & & \\
\hline $\begin{array}{l}\text { MCC2A BUS (Motor } \\
\text { Control Center 2A) }\end{array}$ & 0.48 & 24.99 & 14.34 & 0.04 & 0.02 & 0.083 & 0.000 & No $\mathrm{F}$ & \begin{tabular}{|l|l|} 
PNL & 2
\end{tabular} & 25 & 9 & 18 & 0.39 & Category 0 & & & & \\
\hline $\begin{array}{l}\text { MCC2B B US (Motor } \\
\text { Control }\end{array}$ & 0.48 & 25.02 & 14.36 & 23.98 & 13.76 & 0.008 & 0.000 & No $\mathrm{F}$ & \begin{tabular}{|l|l|} 
PNL & 2 \\
\end{tabular} & 25 & 11 & 18 & 0.53 & Category 0 & \# 0048 & 27.00 & & \\
\hline $\begin{array}{l}\text { MCC2E EUS (Motor } \\
\text { Control Center 2B) }\end{array}$ & 0.48 & 25.02 & 14.36 & 1.05 & 0.60 & 0.083 & 0.000 & No $F$ & \begin{tabular}{|l|l|} 
PNL & 2
\end{tabular} & 25 & 14 & 18 & 0.79 & Category 0 & & & & \\
\hline $\begin{array}{l}\text { MCC4A BUS (Motor } \\
\text { Control Center 4A.) }\end{array}$ & 0.48 & 29.39 & 16.47 & 27.07 & 15.17 & 0.008 & 0.000 & No $\mathrm{F}$ & \begin{tabular}{|l|l} 
PNL & 2
\end{tabular} & 25 & 12 & 18 & 0.62 & Category 0 & \# 0049 & 8.00 & & \\
\hline $\begin{array}{l}\text { MCCAA BUS (Motor } \\
\text { Control Center 4A) }\end{array}$ & 0.48 & 29.39 & 16.47 & 1.75 & 0.98 & 0.016 & 0.000 & No $\mathrm{F}$ & \begin{tabular}{|l|l|} 
PNL & 2
\end{tabular} & 25 & 13 & 18 & 0.67 & Category 0 & & & & \\
\hline $\begin{array}{l}\text { MCCAA, BUS (Motor } \\
\text { Control Center 4A.) }\end{array}$ & 0.48 & 29.39 & 16.47 & 0.01 & 0.01 & 0.083 & 0.000 & No $\mathrm{F}$ & \begin{tabular}{|l|l} 
PNL & 2 \\
\end{tabular} & 25 & 14 & 18 & 0.80 & Category 0 & & & & \\
\hline $\begin{array}{l}\text { MCC4A. BUS (Motor } \\
\text { Control Center 4., }\end{array}$ & 0.48 & 29.39 & 16.47 & 0.42 & 0.24 & 0.083 & 0.000 & No $\mathrm{F}$ & \begin{tabular}{|l|l} 
PNL & 2 \\
\end{tabular} & 25 & 14 & 18 & 0.80 & Category 0 & & & & \\
\hline $\begin{array}{l}\text { MCC4A BUS (Motor } \\
\text { Control Center 4A. }\end{array}$ & 0.48 & 29.39 & 16.47 & 0.01 & 0.00 & 0.083 & 0.000 & No $\mathrm{F}$ & \begin{tabular}{|l|l} 
PNL & 2 \\
\end{tabular} & 25 & 14 & 18 & 0.80 & Category 0 & & & & \\
\hline $\begin{array}{l}\text { MCC4A.EUS (Motor } \\
\text { Control Center 4A.) }\end{array}$ & 0.48 & 29.39 & 16.47 & 0.04 & 0.02 & 0.083 & 0.000 & No $\mathrm{F}$ & \begin{tabular}{|l|l|} 
PNL & 2 \\
\end{tabular} & 25 & 14 & 18 & 0.80 & Category 0 & & & & \\
\hline $\begin{array}{l}\text { MCC4A, EUS (Motor } \\
\text { Control Center 4Q, }\end{array}$ & 0.48 & 29.39 & 16.47 & 0.07 & 0.04 & 0.083 & 0.000 & No $\mathrm{F}$ & \begin{tabular}{|l|l|} 
PNL & 2 \\
\end{tabular} & 25 & 14 & 18 & 0.80 & Category 0 & & & & \\
\hline 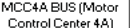 & 0.48 & 29.39 & 16.47 & 0.04 & 0.02 & 0.083 & 0.000 & No & \begin{tabular}{|l|l|} 
PNL & 2 \\
\end{tabular} & 25 & 14 & 18 & 0.80 & Category 0 & & & & \\
\hline MCC4B BUS & $\begin{array}{ll}0.48 \\
\end{array}$ & 28.89 & 16.23 & 27.15 & 15.25 & 0.004 & 0.000 & \begin{tabular}{l|l} 
No & $F$ \\
\end{tabular} & PNL & 25 & 8 & 18 & 0.30 & Category 0 & $\# 0050$ & 12.00 & & \\
\hline MCC4B EUS & 0.48 & 28.89 & 16.23 & 1.75 & 0.99 & 0.083 & 0.000 & No $\mathrm{F}$ & PNL & 25 & 13 & 18 & 0.74 & Category 0 & & & & \\
\hline PTSBUS & 0.48 & 21.21 & 12.46 & 21.01 & 12.35 & 0.004 & 0.000 & \begin{tabular}{l|l} 
No & $F$ \\
\end{tabular} & \begin{tabular}{|l|l|} 
PNL & 2 \\
\end{tabular} & 25 & 7 & 18 & 0.23 & Category 0 & \#0051 & 30.00 & & \\
\hline PTSBUS & 0.48 & 21.21 & 12.46 & 0.21 & 0.12 & 0.083 & 0.000 & No $F$ & \begin{tabular}{|l|l} 
PNL & 2 \\
\end{tabular} & 25 & 8 & 18 & 0.29 & Category 0 & & & & \\
\hline PTSBUS & 0.48 & 21.21 & 12.46 & 0.02 & 0.01 & 0.083 & 0.000 & No $\mathrm{F}$ & PNL & 25 & 8 & 18 & 0.29 & Category 0 & & & & \\
\hline MCC11-PPB EUS & 0.208 & \begin{tabular}{|l|} 
\\
\end{tabular} & 0.84 & 0.96 & 0.84 & 1.101 & 0.000 & Yes $\mathrm{F}$ & FNL & 25 & 18 & 18 & 1.2 & Category 0 ('N15) & \#0012 & & & 1.20 \\
\hline MCC2 1-P PB BUS & 0.208 & 0.96 & 0.84 & 0.96 & 0.84 & 1.102 & 0.000 & Yes $\mathrm{F}$ & PNL & 25 & 18 & 18 & 1.2 & Category 0 ('N15) & \# 0023 & & & 1.20 \\
\hline $\begin{array}{l}\text { MCC4.-PPB BUS } \\
\text { Motor Control Center } \\
\text { 4E] }\end{array}$ & 0.208 & 0.96 & 0.84 & 0.96 & 0.84 & 1.101 & 0.000 & \begin{tabular}{l|l} 
Yes & $\mathrm{F}$
\end{tabular} & \begin{tabular}{|l|l|} 
PNL & 2
\end{tabular} & 25 & 18 & 18 & 1.2 & Category 0 ('N15) & \# 0034 & & & 1.20 \\
\hline Bus-0001 & 12.47 & 4.91 & 4.82 & 0.28 & 0.28 & 0.083 & 0.000 & Yes $\mathrm{s}$ & \begin{tabular}{|l|l|} 
SWG & 15 \\
\end{tabular} & 153 & 11 & 36 & 0.49 & $\begin{array}{l}\text { Category 0 ('N2) } \\
\text { ("N5) }\end{array}$ & & 135.00 & & \\
\hline Dryer Control BUS & 0.48 & 16.98 & 10.31 & 16.22 & 9.85 & 0.06 & 0.000 & \begin{tabular}{l|l} 
No & $F$ \\
\end{tabular} & PNL & 25 & 29 & 18 & 2.7 & Category 1 & $\# 0011$ & 140.00 & & \\
\hline Dryer Control EUS & 0.48 & 16.98 & 10.31 & 0.01 & 0.01 & 0.083 & 0.000 & No $\mathrm{F}$ & \begin{tabular}{|l|l|} 
PNL & 2 \\
\end{tabular} & 25 & 30 & 18 & 2.7 & Category 1 & & & & \\
\hline Dryer Control BUS & 0.48 & \begin{tabular}{|l|l}
16.98 \\
\end{tabular} & 10.31 & 0.02 & 0.01 & 0.083 & 0.000 & No $\mathrm{F}$ & PNL & 25 & 30 & 18 & 2.7 & Category 1 & & & & \\
\hline Dryer Control BuS & 0.48 & 16.98 & 10.31 & 0.53 & 0.32 & 0.083 & 0.000 & No $F$ & \begin{tabular}{|l|l} 
PNL & 2
\end{tabular} & 25 & 30 & 18 & 2.7 & Category 1 & & & & \\
\hline Dryer Control BuS & 0.48 & 16.98 & 10.31 & 0.06 & 0.03 & 0.083 & 0.000 & No $\mathrm{F}$ & FNL & 25 & 30 & 18 & 2.7 & Category 1 & & & & \\
\hline Dryer Control BuS & 0.48 & 16.98 & 10.31 & 0.22 & 0.13 & 0.083 & 0.000 & No $\mathrm{F}$ & PNL & 25 & 30 & 18 & 2.7 & Category 1 & & & & \\
\hline Dryer Control BuS & 0.48 & 16.98 & 10.31 & 0.04 & 0.02 & \begin{tabular}{|c|}
0.083 \\
\end{tabular} & 0.000 & No & FNL & 25 & 30 & 18 & 2.7 & Category 1 & & & & \\
\hline MCCIHEEDSB EUS & 0.48 & 30.07 & 15.75 & 26.90 & 14.09 & 0.06 & 0.000 & \begin{tabular}{l|l} 
No & s
\end{tabular} & SWG & 32 & 42 & 24 & 2.7 & Category 1 & $\# 0022$ & 100.00 & & \\
\hline MCCHOEDSB BUS & $\begin{array}{l}0.48 \\
0.0\end{array}$ & 30.07 & 15.75 & 0.04 & 0.02 & 0.083 & 0.000 & No 5 & SWG & 32 & 43 & 24 & 2.8 & Category 1 & & & & \\
\hline MCCHREDSB BUS & \begin{tabular}{|l|l|}
0.48 \\
0.9
\end{tabular} & 30.07 & $\begin{array}{l}15.75 \\
1575 \\
\end{array}$ & $\begin{array}{l}0.04 \\
004 \\
\end{array}$ & 0.02 & \begin{tabular}{|l|l|}
0.083 \\
0.03
\end{tabular} & 0.000 & No 18 & SWG & 32 & 43 & 24 & 2.8 & Category 1 & & & & \\
\hline $\begin{array}{l}\text { MCCIREDSE BUS } \\
\text { MCCIHQED SB BUS }\end{array}$ & \begin{tabular}{|l|}
0.48 \\
0.48 \\
\end{tabular} & \begin{tabular}{|l|}
30.07 \\
30.07
\end{tabular} & $\frac{15.75}{15.75}$ & $\begin{array}{l}0.04 \\
0.23 \\
\end{array}$ & $\frac{0.02}{0.12}$ & $|0.083|$ & \begin{tabular}{|l|}
0.000 \\
0.000 \\
\end{tabular} & \begin{tabular}{l|l} 
No & $S$ \\
No & s
\end{tabular} & \begin{tabular}{|l|l|} 
SWG \\
SWG
\end{tabular} & $\frac{32}{32}$ & $\begin{array}{ll}43 \\
43\end{array}$ & 24 & $\frac{2.8}{2.8}$ & $\begin{array}{l}\text { Category } 1 \\
\text { Category } 1\end{array}$ & 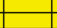 & & & \\
\hline MCCIHQED SB EUS & 0.48 & 30.07 & 15.75 & 0.01 & 0.01 & \begin{tabular}{|l|l|}
0.083 \\
\end{tabular} & \begin{tabular}{|l|l|} 
& 0.000 \\
\end{tabular} & No 5 & SWG & 32 & 43 & 24 & 2.8 & Category 1 & E & & & \\
\hline 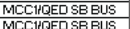 & \begin{tabular}{|l|l|}
0.48 \\
0.48
\end{tabular} & \begin{tabular}{|l|}
30.07 \\
3007
\end{tabular} & $\frac{15.75}{15.75}$ & $\frac{0.04}{280}$ & $\frac{0.02}{147}$ & \begin{tabular}{|l|l|}
0.083 \\
0003
\end{tabular} & \begin{tabular}{|l|l|}
0.000 \\
0000
\end{tabular} & $\begin{array}{ll}\text { No } & \text { s } \\
\end{array}$ & \begin{tabular}{|l|l|l|} 
SWG & 3 \\
SWG & 3
\end{tabular} & 32 & $\frac{43}{43}$ & $\frac{24}{24}$ & $\frac{2.8}{28}$ & $\begin{array}{l}\text { Category } 1 \\
\text { Careocris }\end{array}$ & E & & & \\
\hline $\begin{array}{l}\text { MCCHOEDSB BUS } \\
\text { MCC BUS (Vermeer }\end{array}$ & 0.48 & 30.07 & 15.75 & & 1.47 & 0.083 & 0.000 & No 18 & \begin{tabular}{|l|l|l} 
SWG & 3 \\
\end{tabular} & 32 & 43 & 24 & 2.8 & Category 1 & & 20.00 & & \\
\hline $\begin{array}{l}\text { Motor Control } \\
\text { Enclosure) }\end{array}$ & 0.48 & 27.96 & 13.42 & 25.17 & 12.07 & 0.06 & 0.000 & No $\mathrm{F}$ & FNL 2 & 25 & 35 & 18 & 3.5 & $\begin{array}{l}\text { Category [(N3) } \\
\text { [N5) }\end{array}$ & \# 0057 & 100.00 & & \\
\hline BUS-0039 & $0.48 \mid$ & 34.40 & 16.01 & 9.52 & 5.21 & 0.083 & 0.000 & No $\mathrm{F}$ & PNL & 25 & 53 & 18 & 7.1 & Category 2 & & 15.00 & & \\
\hline $\begin{array}{l}\text { MCC21QREDSB BUS } \\
\text { (MCC2RED } \\
\text { Switchboard) }\end{array}$ & 0.48 & 27.73 & 15.67 & 26.21 & 14.81 & 0.06 & 0.000 & No $F$ & \begin{tabular}{|l|l|} 
PNL & 2
\end{tabular} & 25 & 39 & 18 & 4.2 & Category 2 & $\# 0033$ & 100.00 & & \\
\hline $\begin{array}{l}\text { MCC211EED SB BUS } \\
\text { (MCC21QED } \\
\text { Switchboard) }\end{array}$ & 0.48 & 27.73 & 15.67 & 0.01 & 0.01 & 0.083 & 0.000 & No $\mathrm{F}$ & FNL & 25 & 39 & 18 & 4.3 & Category 2 & & & & \\
\hline $\begin{array}{l}\text { MCC21QED SB BUS } \\
\text { (MCC21QED } \\
\text { Switchboard) }\end{array}$ & 0.48 & 27.73 & 15.67 & 0.01 & 0.01 & 0.083 & 0.000 & No $\mathrm{F}$ & \begin{tabular}{|l|l|} 
PNL & 2
\end{tabular} & 25 & 39 & 18 & 4.3 & Category 2 & & & & \\
\hline $\begin{array}{l}\text { MCC21QED SB BUS } \\
\text { (MCC2RQED } \\
\text { Switchbard) }\end{array}$ & 0.48 & 27.73 & 15.67 & 0.46 & 0.26 & 0.083 & 0.000 & No & PNL & 25 & 39 & 18 & 4.3 & Category 2 & & & & \\
\hline $\begin{array}{l}\text { MCC21QED SB BUS } \\
\text { (MCC21QED } \\
\text { Switchboard) }\end{array}$ & 0.48 & 27.73 & 15.67 & 1.05 & 0.59 & 0.083 & 0.000 & No $\mathrm{F}$ & PNL & 25 & 39 & 18 & 4.3 & Category 2 & & & & \\
\hline $\begin{array}{l}\text { MCC4QRED SB BUS } \\
\text { (MCC4QED } \\
\text { Switchboard) }\end{array}$ & 0.48 & 30.32 & 16.91 & 26.22 & 14.63 & 0.06 & 0.000 & No & \begin{tabular}{|l|l|} 
PNL & 2
\end{tabular} & 25 & 41 & 18 & 4.6 & Category 2 & $\# 0045$ & 100.00 & & \\
\hline $\begin{array}{l}\text { MCCALEED SB BUS } \\
\text { (MCC4RED } \\
\text { Switchbard) }\end{array}$ & 0.48 & 30.32 & 16.91 & 0.04 & 0.02 & 0.083 & 0.000 & No & PNL & 25 & 42 & 18 & 4.8 & Category 2 & & & & \\
\hline $\begin{array}{l}\text { MCC4QQED SB EUS } \\
\text { (MCC4LED } \\
\text { Switchboard) }\end{array}$ & 0.48 & 30.32 & 16.91 & 2.34 & 1.30 & 0.083 & 0.000 & No & FNL & 25 & 42 & 18 & 4.8 & Category 2 & & & & \\
\hline $\begin{array}{l}\text { MCC4IQED SB BUS } \\
\text { (MCC4QRED } \\
\text { Switchboard) }\end{array}$ & 0.48 & 30.32 & 16.91 & 1.75 & 0.98 & 0.083 & 0.000 & No & PNL & 25 & 42 & 18 & 4.8 & Category 2 & & & & \\
\hline $\begin{array}{l}\text { QED MAIN } \\
\text { SWITCHGEAR }\end{array}$ & 0.48 & 34.24 & 15.95 & 1.51 & 0.83 & 0.083 & 0.000 & No & PNL & 25 & 53 & 18 & 7.1 & Category 2 & & & & \\
\hline $\begin{array}{l}\text { QEDMAIN } \\
\text { SWITTHGEAR }\end{array}$ & $0.48 \mid$ & \begin{tabular}{|c|}
34.24 \\
\end{tabular} & 15.95 & 0.85 & 0.47 & 0.083 & 0.000 & No $\mathrm{F}$ & \begin{tabular}{|l|l|} 
PNL & 2
\end{tabular} & 25 & 53 & 18 & 7.1 & Category 2 & & & & \\
\hline $\begin{array}{l}\text { QEDMAIN } \\
\text { SWITCHGEAR }\end{array}$ & 0.48 & 34.24 & 15.95 & 4.04 & 2.21 & 0.083 & 0.000 & No $F$ & \begin{tabular}{|l|l|l|} 
PNL & 2 \\
\end{tabular} & 25 & 53 & 18 & 7.1 & Category 2 & & & & \\
\hline $\begin{array}{l}\text { QEDMAIN } \\
\text { SWITCHGEAR } \\
\end{array}$ & 0.48 & 34.24 & 15.95 & 276 & 1.51 & 0.083 & 0.000 & No $\mathrm{F}$ & PNL & 25 & 53 & 18 & 7.1 & Category 2 ('N5) & & 20.00 & & \\
\hline BUS-0001 & 12.47 & 4.91 & 4.82 & 4.63 & 4.55 & 1000 & $\begin{array}{l}0.000 \\
\end{array}$ & \begin{tabular}{l|l} 
Yes & $\mathrm{s}$ \\
\end{tabular} & \begin{tabular}{|l|l|} 
Swa & 10 \\
\end{tabular} & \begin{tabular}{l|l}
153 & 2 \\
\end{tabular} & 209105 & 36 & 5493 & $\begin{array}{l}\text { Dangerous! (N2) } \\
\text { [N9] }\end{array}$ & $\# 0001$ & & & \\
\hline BUS-0039 & 0.48 & 34.40 & 16.01 & 24.88 & 11.58 & 8.333 & 0.000 & No 1 & PNL 2 & 25 & 663 & 18 & 444 & Dangerous! (NN3) & $\# 0010$ & & & \\
\hline $\begin{array}{l}\text { QEDMAIN } \\
\text { SWITCHGEAR }\end{array}$ & 0.48 & 34.24 & 15.95 & 24.70 & 11.51 & 0.847 & 0.000 & No & PNL & 25 & 167 & 18 & 46 & Dangerous! ('N3) & $\# 0056$ & & & \\
\hline $\begin{array}{l}\text { Category 0: Untreated } \\
\text { Cotton }\end{array}$ & & & & & & & & & & & & & $\#$ \# $a x=10$ & \multicolumn{5}{|c|}{$\frac{1}{1}$ (N2) $80 \%$ Cleared F ault Threshold } \\
\hline $\begin{array}{l}\text { Category 1: FR Shirt \& } \\
\text { Pants }\end{array}$ & & & & & & & & & & & & & \#Cat $1=3$ & \multicolumn{5}{|c|}{ ['N3]-Arcing Current Low Tolerances Used } \\
\hline $\begin{array}{l}\text { Category 2:Cotton } \\
\text { Inderwear FF Shirt \& }\end{array}$ & & & & & & & & & & & & & $\#$ \#аt $2=2$ & \multicolumn{5}{|c|}{ ("N5) - Miscooordinated, Upstream Device Tripped } \\
\hline 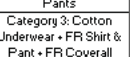 & & & & & & & & & & & & & $\#$ Еат $3=0$ & \multicolumn{5}{|c|}{ ['N9]-Max Arcing Duration Reached } \\
\hline 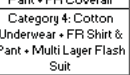 & & & & & & & & & & & & & $\#$ Cat $4=0$ & \multirow{2}{*}{\multicolumn{5}{|c|}{$\begin{array}{l}\text { ('N15) - Report as oategory 0iffed by one transformer size < } 125 \\
\mathrm{kVA}\end{array}$}} \\
\hline $\begin{array}{l}\text { Category Dangerous: } \\
\text { FRP }\end{array}$ & & & & & & & & & & & & & \#D anger = 3 & & & & & \\
\hline
\end{tabular}




\section{Ground Review}

As part of the BioMass PDU project analysis, grounding and multi-state code reviews were performed. The $480 \mathrm{~V}$ system has been considered in the review process and has been checked against three possible system configurations, a four-wire grounded system, a four-wire high-impedance system, and a three-wire delta system. As part of this review, it was suggested that the equipment grounding system and the static/lightning protections systems be integrated into one ground-wire system.

The system will have loads delta connected; this includes motors, step-down transformers, and variable-speed drives. Given the three possible system configurations, there are different code sections to which they must adhere.

For the four-wire grounded system, $\{\S 250.20(B)(2)\}$ of the National Electric Code must be followed, explaining a neutral grounded system. The neutral conductor must be run to each subpanel that is listed as a four-wire panel.

For a four-wire high-impedance grounded system, $\{\S 250.20(\mathrm{E})\}$ of the National Electric Code must be followed, specifically explaining the neutral high-impedance grounded system.

For a three-wire delta system, $\{\S 250.20(\mathrm{D}) ; \S 250.21(\mathrm{~A})(4)\}$ of the National Electric Code must be followed for an ungrounded system. It is specifically noted that the panels must be listed and rated for an ungrounded delta system.

The size of the grounding electrode conductor where supplied by a feeder or branch circuit or at a separately derived system of a grounded or an ungrounded alternating current system shall not be less than given in Table 250.66, except as permitted in 250.66(A) - (C) of the NEC.

Figure 4 represents the grounded system as applied to the BioMass PDU application. 


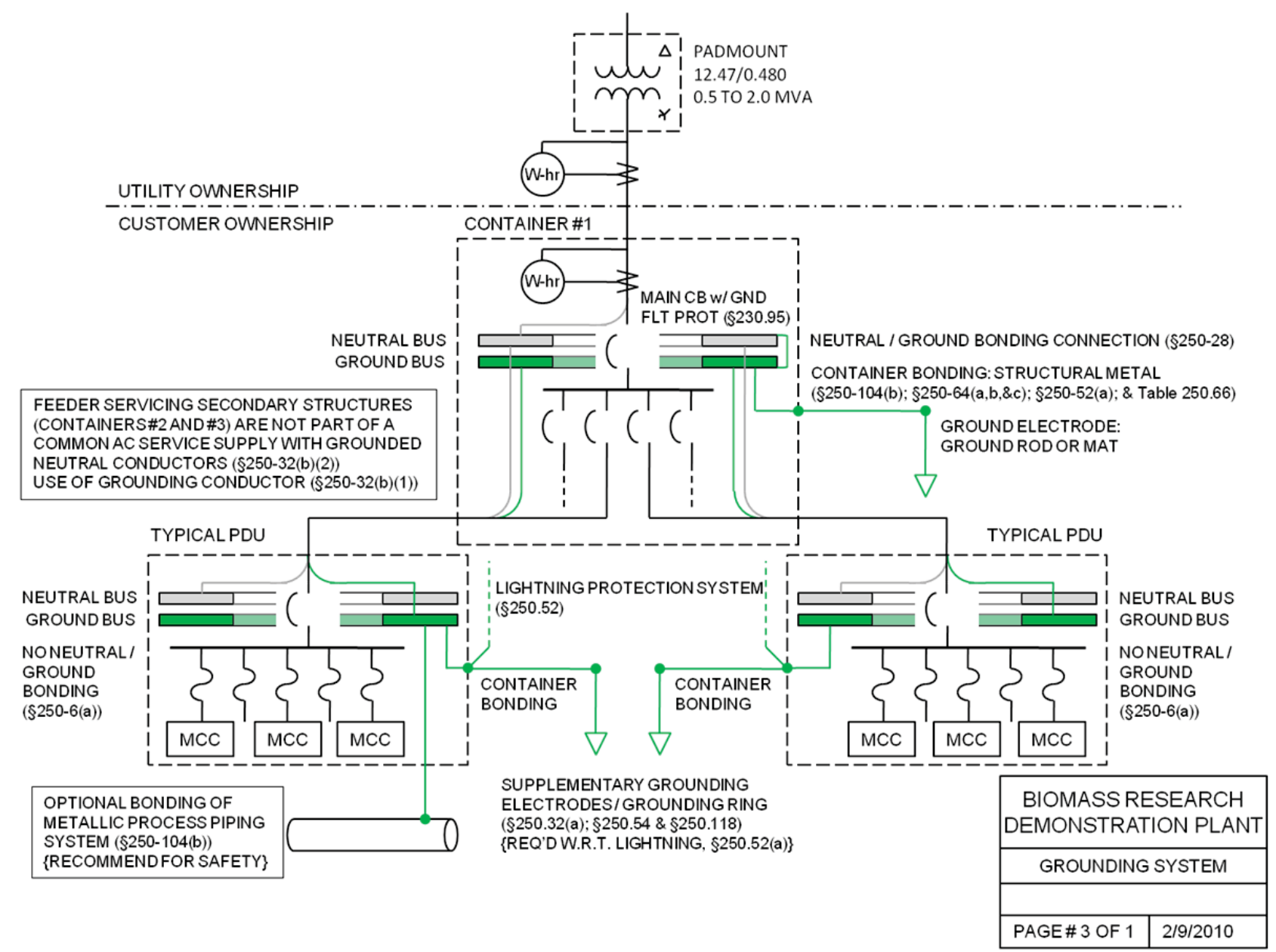

Figure 4. Biomass PDU grounding description. 


\section{Multi-State Code Review}

The BioMass PDU project will not be a permanent unit. It will be a mobile unit that could spend time in any state across the nation. This changes the typical standards review that most electrical projects go through. The fact that multiple states could be involved requires the review of every state's electric code requirements for such a unit. The major concern for the multi-state code review was directed toward the review of Code Section 250 in the National Electric Code. This section describes the Grounding and Bonding requirements.

A few comment definitions as they apply to the BioMass PDU project are as follows:

- Standard Application-The code is applied in a standard fashion as with any project. Material selection or implementation choices are at the discretion of the project manager.

- Specifically Applied-The project must address or implement this particular part of the code.

- N/A - Generally, not applicable to this project as it has been defined.

The following table shows the sections of Article 250 and how they relate to the BioMass PDU project as defined.

\begin{tabular}{|l|l|l|l|l|l|}
\hline Section & Comment & Section & Comment & Section & Comment \\
\hline 250.3 & & 250.30 & Standard application & $250.80-86$ & Standard application \\
\hline $250.4($ A) & Applicable & 250.34 & n/a & $250.90-98$ & Standard application \\
\hline $250.4(B)$ & n/a & 250.36 & Applicable for Hi-Z & 250.100 & Specifically applies \\
\hline 250.6 & Standard application & 250.50 & Standard application & $250.102-104$ & Standard application \\
\hline 250.8 & Standard application & 250.52 & Specifically applies & 250.106 & Specifically applies \\
\hline 250.10 & Standard application & 250.53 & Standard application & $250.110-112$ & Standard application \\
\hline 250.12 & Standard application & 250.54 & Specifically applies & $250.114-119$ & Specifically applies \\
\hline 250.20 & $\begin{array}{l}\text { Permissible configurations: } \\
\text { (B)(2);(D)(see 250.30) or (E) }\end{array}$ & 250.60 & Specifically applies & 250.120 & Standard application \\
\hline 250.21 & Applicable for UG (A)(4) & 250.62 & Standard application & $250.122-124$ & Specifically applies \\
\hline 250.22 & n/a & 250.64 & Standard application & $250.130-148$ & Standard application \\
\hline 250.24 & Applicable, especially (A)(2) & 250.66 & Specifically applies & $250.170-176$ & n/a \\
\hline 250.26 & Applicable: (3) only & 250.68 & Specifically applies & $250.170-176$ & n/a \\
\hline 250.28 & Use Table 250.66 & 250.70 & Standard application & $250.180-186$ & n/a \\
\hline
\end{tabular}

Figure 5. 2008 NEC code review for Article 250.

The following map is from the National Electric Manufacturers Association (NEMA) and is intended to provide information on the current adoptions of the NEC to local jurisdictions. It is intended to be used by the project manager to ensure that the installation meets local code requirements. 


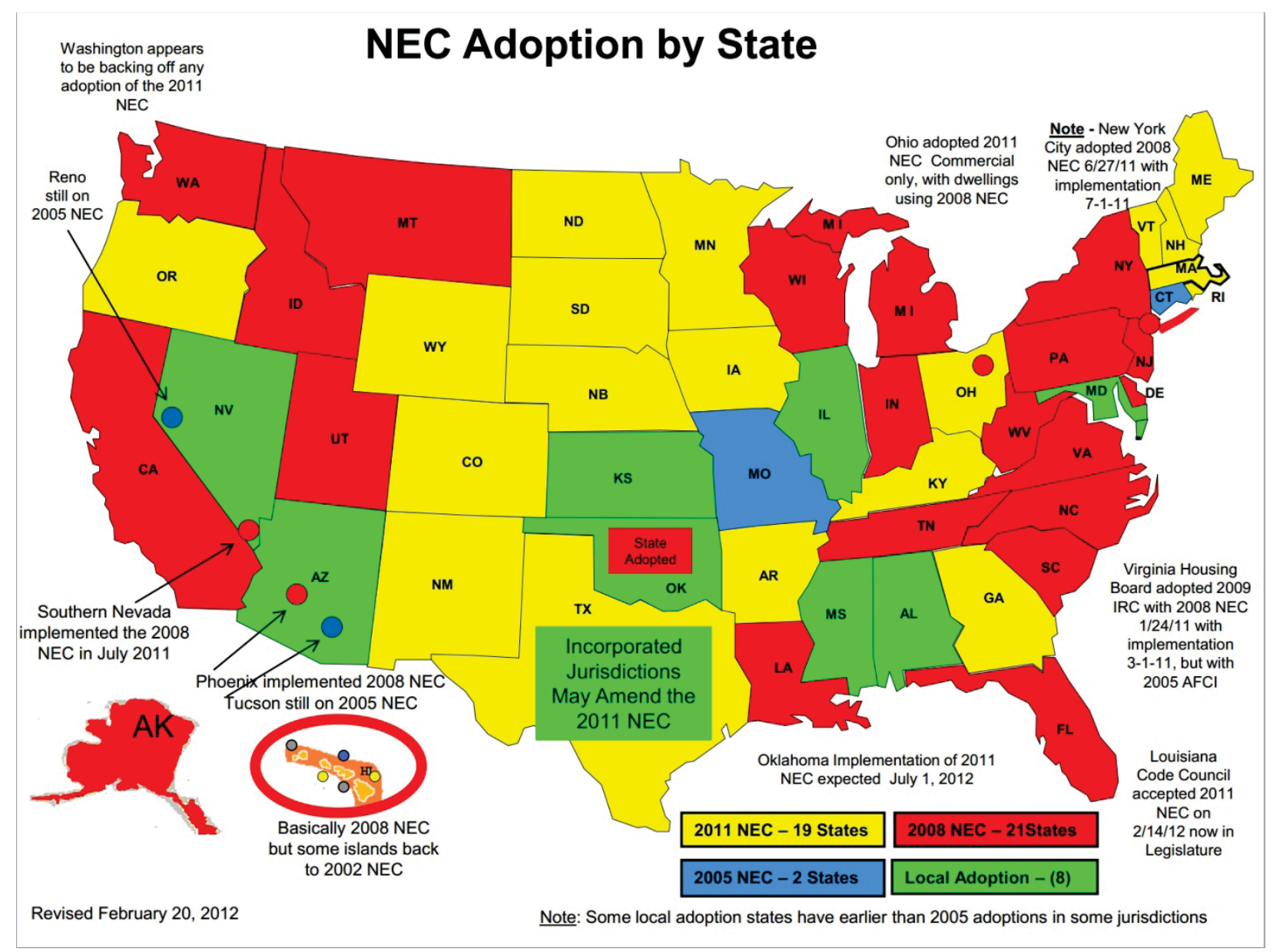

Figure 6. 2011 NEC adoptions by state. 


\section{Appendix A}

\section{Input Data}

\section{Conductors}

[NOTE: Ctrl+click on the image to open the PDF file.]

\begin{tabular}{|c|c|c|c|c|c|c|c|c|}
\hline \multirow{3}{*}{$\begin{array}{l}\text { BRANCC NAME } \\
\text { Uutility Underground }\end{array}$} & OMNAME & ONAME & TYPE & Phase & & & & PATING \\
\hline & & Uus-0002 & FDR & (A) & 0.02 & 72.4 & 516.3: & \\
\hline & & & & B) & 0.03 & $\frac{84}{795}$ & $\frac{601.1}{6553}$ & \\
\hline \multirow{2}{*}{ Utility Supplied } & Bus-0002 & Bus-0039 & $\overline{x \rightarrow 3}$ & (A) & 3.09 & $\frac{7.24}{72.4}$ & $\frac{15.25}{516.25}$ & 90. \\
\hline & & & & th & 11.73 & 84.5 & 600.93 & \\
\hline \multirow{2}{*}{$\overline{M o c 1}$ Feder Cable } & OED MAIN SWITCHGEAR & CC1/OED SB BUS & FDR & A) & & $\frac{26.7}{56.7}>2>$ & & \\
\hline & & & & 6) & 0.3 & $\frac{660.2}{60}$ & & \\
\hline \multirow{3}{*}{$\overline{\text { Moc2 Feeder Cable }}$} & 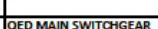 & (1) & Fn & c) & 0.3. & 621.88 & 160.53 & 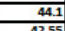 \\
\hline & & & & & & 460.6 & & \\
\hline & & & & c) & 0.36 & 4433.0 & 114.37 & \\
\hline \multirow{2}{*}{ Dryer Feeder Cable } & DEEDMAIN SWTCCHGEAR & Drver Control & FDR & A) & 0.55 & 1466.5 & 41.42 & \\
\hline & & & - & (c) & $\frac{0.0}{0.6}$ & 160.65 & \begin{tabular}{|l|l|l|l|l|}
4148 \\
\end{tabular} & $\frac{79.92}{69.87}$ \\
\hline \multirow[t]{2}{*}{ MocA Feeder cable } & OEDD MAIN SWICHGEAR & MCCA/AED SB BUS & FDR & (A) & 0.4 .4 & 769.4 .4 & 217.45 & 5450 \\
\hline & & & & (B) & $\frac{0.45}{0.44^{5}}$ & $\frac{9021.1}{8410}$ & $\frac{217.75}{2171}$ & $\frac{639.9}{596.5}$ \\
\hline \multirow{2}{*}{ Main feeder cable } & Eus-0039 & OEDD MAIN SWICHGEAR & FDR & (A) & $\frac{0.45}{0.06}$ & $\frac{242101}{188278}$ & \begin{tabular}{|l|l|}
5322 \\
532.
\end{tabular} & $\frac{396.0}{66.0}$ \\
\hline & & & & $\frac{(B)}{(C)}$ & 0.0 & $\frac{2195.35}{20656.5}$ & $\frac{529.5}{53.38}$ & $\frac{77.0}{725}$ \\
\hline \multirow{2}{*}{$\mathrm{MOC2CBD1}$} & MCC2/Q/OED SB BUS & EUS-0009 & FOR & $\frac{1}{(A)}$ & $\frac{0.1}{0.1}$ & $\frac{15.7}{15.7}$ & $\frac{5.44}{4.44}$ & \\
\hline & & & $\square$ & (B) & 0.2 & 18.52 & 4.44 & 5 \\
\hline \multirow{2}{*}{$\mathrm{MCC2CBL2}$} & MCC2/OFE SB BUS & BUS-0010 & FOR & $\frac{1}{(A)}$ & $\frac{0.19}{0.02}$ & 1.7 .4 & 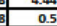 & \\
\hline & & & $\square$ & (B) & 0.02 & 2.05 & 0.5 & 5.5 \\
\hline \multirow{2}{*}{$\mathrm{MCC2CBl3}$} & MCC2/OED SB BUS & BUS-0043 & FDR & (A) & $\frac{0.00}{0.00}$ & $\frac{23}{23}$ & 0.67 & $\frac{5 .}{6 .}$ \\
\hline & & & $\square$ & (B) & 0.03 & 2.74 & 0.67 & 7.6 \\
\hline \multirow[t]{2}{*}{$\mathrm{MCC2} 2 \mathrm{CB} / 4$} & MCC2/OED SB BUS & BUs-0012 & FDR & $\frac{1(1)}{(\Delta)}$ & $\frac{0.36}{0.16}$ & $\begin{array}{r}78.82 \\
\end{array}$ & $\begin{array}{l}22.21 \\
2\end{array}$ & 68.5 \\
\hline & & & & & & & & \\
\hline \multirow{2}{*}{ MOC2 CBL5 } & MCC2/OFE D S B BUS & MCC2ABUS & FDR & a) & 0.0 & & 2185 & \\
\hline & & & 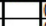 & (B) & 0.05 & 91.22 & 21.89 & 年9 \\
\hline \multirow{2}{*}{$\mathrm{MOC2} 2 \mathrm{CB} 6 \mathrm{6}$} & MCC2/QQED SB BUS & Moc28 BUS & FOR & A) & 0.05 & 193.32 & $\frac{55.59}{59}-1$ & \\
\hline & & & & B) & 0.0 & 222.5 & 53.41 & $\frac{58}{58},-3$ \\
\hline \multirow{3}{*}{$\mathrm{MOC2} 2 \mathrm{CBL}$} & 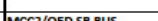 & 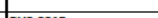 & -1 & & 0 & 220.8 & 56.8 & \\
\hline & $B C C 2 / O A=D S B B U S$ & BUS-0015 & Fon & & $\frac{0.2}{0}$ & $\frac{13.7}{18.5}>0$ & 4.440 & \\
\hline & & & $\square$ & (c) & 0.1 & $\frac{17.2 .}{172}$ & 4.44 & $\frac{49}{49}-2>$ \\
\hline \multirow{2}{*}{$\mathrm{MCC2} 2 \mathrm{CBL}$} & MCC2/QED SB BUS & Bus-0069 & FDR & $\Delta)_{1}$ & 0.27 & 10.65 & $3^{3}$ & 42. \\
\hline & & & & & $\frac{0.2}{0.2}+2$ & & & \\
\hline \multirow{2}{*}{ MOCACBL1 } & MCCA//OED SB BUS & $\begin{array}{ll}\text { BUS5-0018 } \\
\end{array}$ & $\begin{array}{lll}\text { PDR } & \\
\end{array}$ & ti & 0.1 & $\overline{15.7}>>>$ & & \\
\hline & & & $\square$ & [B] & 0 & 18.5 & 4.44 & 52 \\
\hline Mcacaly & SCCO/OEDSPRYS & 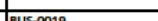 & -1 & & 0.1 & 17. & 4.44 & \\
\hline 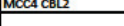 & MCCA/OFE SB BUS & BUS-0019 & FRR & & $\frac{0.1}{3}>>1$ & 15.7 & 4.44 4.4 & 57 \\
\hline & & & & & & & & \\
\hline$\overline{M O C A C B L 5}$ & $M C C A / \mathrm{OED}$ SB BUS & MCCAA BUS & FDR & & 0.0 & $\frac{363}{3963} \mathrm{rat}$ & $11156 \mathrm{~s}$ & \\
\hline & & & $\square$ & (B) & 0.0 & 465.8. & 111.66 & \\
\hline MCCACB16 & ACCO/OEDSP PUS & Mcrap pus & ( & & 0.0 & 134.4 & 111611 & 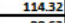 \\
\hline Mecaco616 & 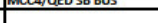 & mectabious & 年 & & $\frac{0.0}{00}$ & & & $98+9$ \\
\hline 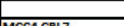 & 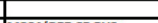 & ( & $\square$ & - & 0.06 & 333.48 & \begin{tabular}{|l|l|}
85.67 \\
\end{tabular} & 87 \\
\hline & & & som & & & & 404 & \\
\hline & & & & & & 17. & 444 & \\
\hline 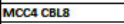 & MCCA//OED SB BUS & BUS-0025 & FDR & (A) & 0.1 & 13.45 & 3.78 & \\
\hline & & & & & 0 & 15.76 & 3.78 & \\
\hline Dryer CBL1 & Dryer control & SBUS-0070 & Eppet t r & & 0.0 & $\frac{14}{20}$ & $\frac{3.367}{0.57}>0$ & \\
\hline & & & $\square$ & & 0.0 & 233 & 0.57 & 9 \\
\hline Dryer CBLI2 & Diver Control & Bus-0071 & FDQ & & $\frac{0.0}{0.0}>>2$ & & $\frac{0.57}{0.72}$ & \\
\hline & & & t & 3) & 0.09 & $=$ & 0.72 & \\
\hline Drere CBI3 & $\mid$ & BUS-0072 & EDQ & & $\frac{0.0}{0.1}$ & $\frac{21}{893}$ & $\frac{.027}{2.25}$ & \\
\hline & & & t & & $\frac{0.1}{0.1}$ & $\frac{0.51}{105}$ & $\frac{25.12}{25.12}$ & \\
\hline Drerçal4 & Dryer Control & BUS-0073 & 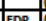 & & & & 25.11 & \\
\hline (5) & 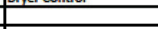 & & 政 & & 0.15 & 11.16 & 2.67 & $\frac{31}{44}$ \\
\hline DNer CB15 & Dirver control & Bus-0074 & FDR & & $\frac{0.17}{0.17}$ & \begin{tabular}{|l|l|}
10.41 \\
3.604
\end{tabular} & \begin{tabular}{|l|}
267 \\
1000
\end{tabular} & \\
\hline & & & | & & 0.2. & 42.8. & 10.25 & \\
\hline & & & & & & 9 & . 0.25 & \\
\hline
\end{tabular}




\section{Transformer}

[NOTE: Ctrl+click on the image to open the PDF file.]

\begin{tabular}{|c|c|c|c|c|}
\hline 2-Winding Transformer & |Phase & $(k W)$ & (kVAR) & Pctivdi(\%) \\
\hline \multirow[t]{3}{*}{ WIilily Suppliced XFRMR } & A: & 426.3 & 318.9 & 3.09 \\
\hline & D: & 423.9 & 317.4 & 11.73 \\
\hline & $\mathrm{C}:$ & 123.3 & 322.1 & 3.18 \\
\hline \multirow[t]{3}{*}{ MCC1 Dist XГRMR } & A: & 1.9 & 1.4 & 5.26 \\
\hline & D: & 1.6 & 1.2 & 2.69 \\
\hline & $\mathrm{C}:$ & 3.2 & 2.3 & 0.39 \\
\hline \multirow[t]{3}{*}{ MCC2 Dist XГRMR } & A: & 4.1 & 3.1 & 7.79 \\
\hline & $\mathrm{B}:$ & 1.1 & 1.2 & 2.81 \\
\hline & $C:$ & 5.5 & 4 & 2.42 \\
\hline \multirow[t]{3}{*}{ MCC4 Dist XГRMR } & A: & 1.8 & 1.3 & 5.1 \\
\hline & $\mathrm{B}:$ & 1.5 & 1.2 & 2.65 \\
\hline & $C:$ & 1.6 & 1.2 & 2.24 \\
\hline
\end{tabular}




\section{Utility}

[NOTE: Ctrl+click on the image to open the PDF file.]

\begin{tabular}{l|l|r|r|r} 
Utility & Phase & (kW) & (kVAR) & PctVD(\%) \\
\hline UIility & A & 411.19 & 312.35 & 1.03 \\
\hline & B & 481.34 & 360.05 & 1.2 \\
\hline & $\mathrm{C}$ & 103.1 & 396.38 & 1.29
\end{tabular}


Loads

[NOTE: Ctrl+click on the image to open the PDF file.]

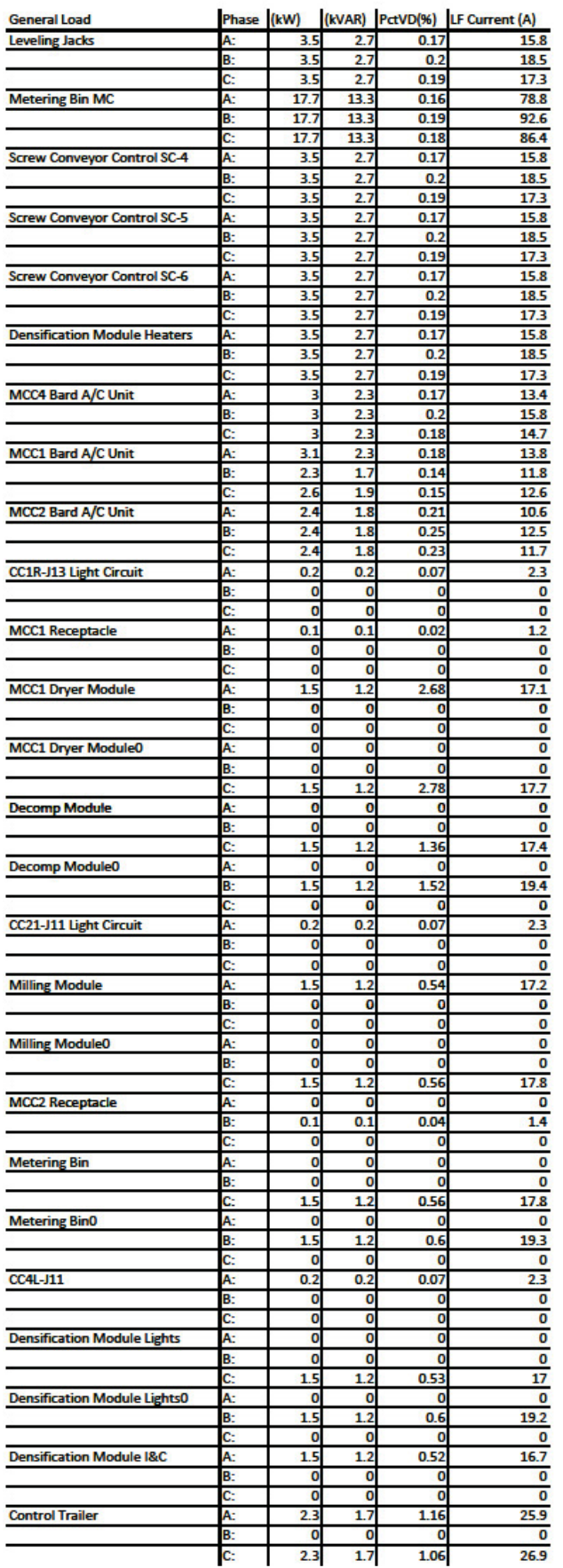


Motors

[NOTE: Ctrl+click on the image to open the PDF file.]

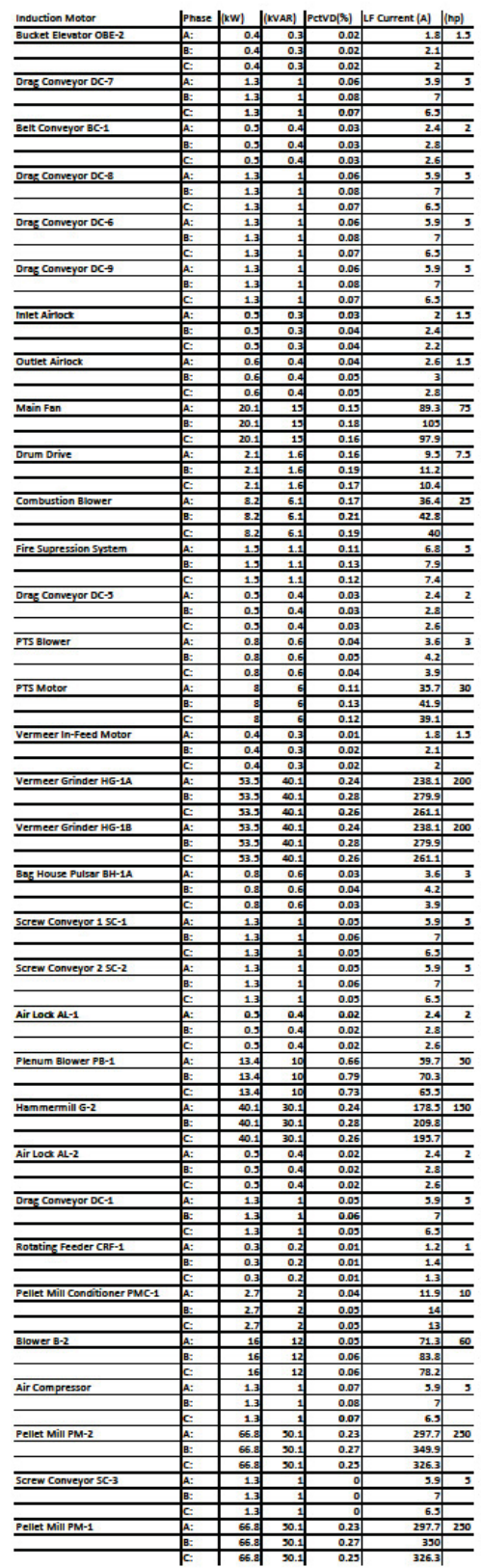




\section{Breakers}

[NOTE: Ctrl+click on the image to open the PDF file.]

\begin{tabular}{|c|c|c|c|}
\hline Ev Breaters & Description & 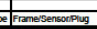 & Sesmuses \\
\hline & SOUARED & & 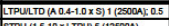 \\
\hline & $51,600-2500 A, U$ & & 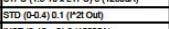 \\
\hline & 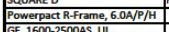 & 50000 & 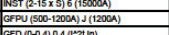 \\
\hline TSiin SCBI & S & traces & 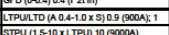 \\
\hline & 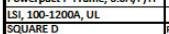 & & 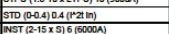 \\
\hline & 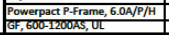 & socon & 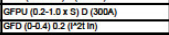 \\
\hline $\mathrm{ASCBZ}_{2}$ & & & 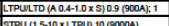 \\
\hline & 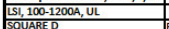 & 2 & 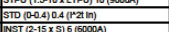 \\
\hline & 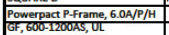 & $\frac{0.04}{0.04}$ & 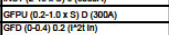 \\
\hline Nain ICB33 & 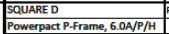 & $\int_{120004}^{20004}$ & 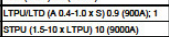 \\
\hline & 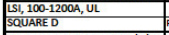 & $2000 x$ & 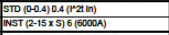 \\
\hline & 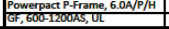 & & 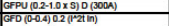 \\
\hline Nasian SCBA & 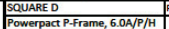 & 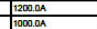 & 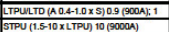 \\
\hline & 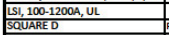 & & 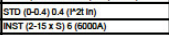 \\
\hline & 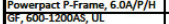 & & \\
\hline MCCI Main & SQUARED & 20000 & 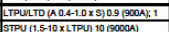 \\
\hline & 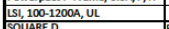 & & 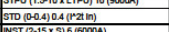 \\
\hline & 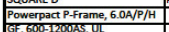 & 10000 & 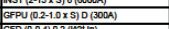 \\
\hline ICCCMain & 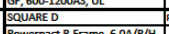 & 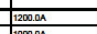 & 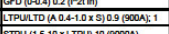 \\
\hline & 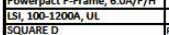 & & 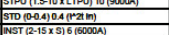 \\
\hline & 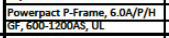 & 8004 & 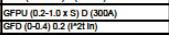 \\
\hline ex Main & 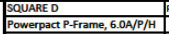 & 200000 & 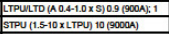 \\
\hline & 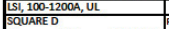 & 2000 & 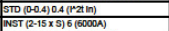 \\
\hline & 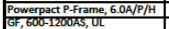 & soan & 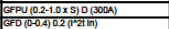 \\
\hline 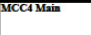 & 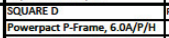 & 2000 & 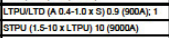 \\
\hline & 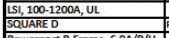 & & 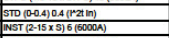 \\
\hline & 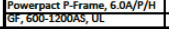 & & 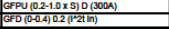 \\
\hline reaker & & $\frac{5 a n}{5 a n}$ & \\
\hline ralaken & $\begin{array}{l}1 \text { 15-150A } \\
\text { SOCOARED }\end{array}$ & & Fined \\
\hline & $\begin{array}{ll}1-150 A \\
150 A\end{array}$ & $\operatorname{sen}$ & \\
\hline Ver Brateres & $\begin{array}{l}\text { SOUARED } \\
\text { WO }\end{array}$ & $250 \mathrm{an}$ & Fined \\
\hline 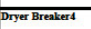 & STUARED & 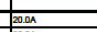 & inea \\
\hline & 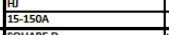 & $=$ & \\
\hline & & 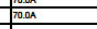 & \\
\hline realerer & SQUAREI & $\frac{1509}{1509}$ & rese \\
\hline$\overline{C C A M A C C}$ & $\begin{array}{ll}15-150 A \\
\text { SQRARE D }\end{array}$ & 120000 & 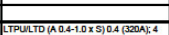 \\
\hline & 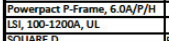 & toonen & 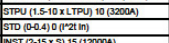 \\
\hline
\end{tabular}




\section{Fuses}

[NOTE: Ctrl+click on the image to open the PDF file.]

\begin{tabular}{|c|c|c|c|}
\hline Fuses & Description & FFAMEMOOEL & Cartriogentip \\
\hline \multirow[t]{3}{*}{ Utility Fuse } & SQUARE D & CS-3, 100E & $100.0 \mathrm{~A}$ \\
\hline & CS-3, 15.5kV E-Rated & & $100.0 \mathrm{~A}$ \\
\hline & $10 \mathrm{E}-100 \mathrm{E}$ & & \\
\hline \multirow[t]{3}{*}{ MCC1 Fuse 1} & BUSSMANN & JKS & $30.0 \mathrm{~A}$ \\
\hline & IKS, 600V Class I & & $30.0 \mathrm{~A}$ \\
\hline & $1-600 \mathrm{~A}$ & & \\
\hline \multirow[t]{3}{*}{ MCC1 Fuse 2 } & BUSSMANN & JKS & $30.0 \mathrm{~A}$ \\
\hline & IKS, 600V Class I & & $30.0 \mathrm{~A}$ \\
\hline & $1-600 \mathrm{~A}$ & & \\
\hline \multirow[t]{3}{*}{ MCC1 Fuse 3} & BUSSMANN & JJKS & $30.0 \mathrm{~A}$ \\
\hline & IKS, 600V Class I & & $30.0 \mathrm{~A}$ \\
\hline & $1-600 \mathrm{~A}$ & & \\
\hline \multirow[t]{3}{*}{ MCC1 Fuse 4} & BUSSMANN & JKS & $100.0 \mathrm{~A}$ \\
\hline & IKS, 600V Class I & & $100.0 \mathrm{~A}$ \\
\hline & $1-600 \mathrm{~A}$ & & \\
\hline \multirow[t]{3}{*}{ MCC1 Fuse 5} & BUSSMANN & JKS & $400.0 \mathrm{~A}$ \\
\hline & |IKS, 600V Class I & & $400.0 \mathrm{~A}$ \\
\hline & $1-600 A$ & & \\
\hline \multirow{3}{*}{ MCC1Fuse 6} & BUSSMANN & JKS & $400.0 \mathrm{~A}$ \\
\hline & JKS, 600V Class I & & $400.0 \mathrm{~A}$ \\
\hline & $1-600 \mathrm{~A}$ & & \\
\hline \multirow[t]{3}{*}{ MCC1 Fuse 7} & BUSSMANN & JKS & $30.0 \mathrm{~A}$ \\
\hline & KKS, 600V Class I & & $30.0 \mathrm{~A}$ \\
\hline & $1-600 \mathrm{~A}$ & & \\
\hline \multirow[t]{3}{*}{ MCC1 Fuse 8} & BUSSMANN & JJKS & $30.0 \mathrm{~A}$ \\
\hline & |JKS, 600V Class I & & $30.0 \mathrm{~A}$ \\
\hline & $11-600 \mathrm{~A}$ & & \\
\hline \multirow[t]{3}{*}{ MCC1Fuse 9 } & BUSSMANN & JJKS & $100.0 \mathrm{~A}$ \\
\hline & IKS, 600V Class I & & $100.0 \mathrm{~A}$ \\
\hline & $1-600 \mathrm{~A}$ & & \\
\hline MCC1 PTS Fuse 1 & BUSSMANN & 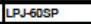 & $60.0 \mathrm{~A}$ \\
\hline & (LPJ_SP, 600V Class J & & $60.0 \mathrm{~A}$ \\
\hline & $15-600 \mathrm{~A}$ & & \\
\hline MCC1 PTS Fuse 2 & BUSSMANN & LPJ-30SP & $30.0 \mathrm{~A}$ \\
\hline & [LP]_SP, 600V Class J & & $30.0 \mathrm{~A}$ \\
\hline & $15-600 \mathrm{~A}$ & & \\
\hline MCC2 Fuse 1 & BUSSMANN & JJKS & $30.0 \mathrm{~A}$ \\
\hline & IKS, 600V Class I & & $30.0 \mathrm{~A}$ \\
\hline & $1-600 \mathrm{~A}$ & & \\
\hline MCC2 Fuse 2 & BUSSMANN & JJKS & $30.0 \mathrm{~A}$ \\
\hline & |jKS, 600V Class I & & $30.0 \mathrm{~A}$ \\
\hline & $1-600 \mathrm{~A}$ & & \\
\hline MCC2 Fuse 3 & BUSSMANN & JJKS & $30.0 \mathrm{~A}$ \\
\hline & KKS, 600V Class I & & $30.0 \mathrm{~A}$ \\
\hline & $1-600 \mathrm{~A}$ & & \\
\hline MCC2 Fuse 4 & BUSSMANN & JKS & $100.0 \mathrm{~A}$ \\
\hline & IKS, 600V Class I & & $100.0 \mathrm{~A}$ \\
\hline & $1-600 A$ & & \\
\hline MCC2Fuse 5 & BUSSMANN & JKS & $200.0 \mathrm{~A}$ \\
\hline & IKS, 600V Class I & & $200.0 \mathrm{~A}$ \\
\hline & $1-600 \mathrm{~A}$ & & \\
\hline MCC2 Fuse 6 & BUSSMANN & JKS & $800.0 \mathrm{~A}$ \\
\hline & IKS, 600V Class I & & $450.0 \mathrm{~A}$ \\
\hline & $1-600 \mathrm{~A}$ & & \\
\hline MCC2 Fuse 7 & BUSSMANN & JKS & $30.0 \mathrm{~A}$ \\
\hline & |JKS, 600V Class I & & $30.0 \mathrm{~A}$ \\
\hline & $1-600 \mathrm{~A}$ & & \\
\hline MCC2 Fuse 8 & BUSSMANN & JJKS & $100.0 \mathrm{~A}$ \\
\hline & IKS, 600V Class I & & $100.0 \mathrm{~A}$ \\
\hline & $1-600 \mathrm{~A}$ & & \\
\hline MCC2 Fuse 9 & BUSSMANN & JKS & $100.0 \mathrm{~A}$ \\
\hline & IKS, 600V Class I & & $100.0 \mathrm{~A}$ \\
\hline & $1-600 \mathrm{~A}$ & & \\
\hline MCC4Fuse 1 & BUSSMANN & JJKS & $30.0 \mathrm{~A}$ \\
\hline & IKS, 600V Class I & & $30.0 \mathrm{~A}$ \\
\hline & $1-600 \mathrm{~A}$ & & \\
\hline MCC4 Fuse 2 & BUSSMANN & JKS & $30.0 \mathrm{~A}$ \\
\hline & |jKS, 600V Class I & & $30.0 \mathrm{~A}$ \\
\hline & $1-600 \mathrm{~A}$ & & \\
\hline MCC4 Fuse 3 & BUSSMANN & JJKS & $30.0 \mathrm{~A}$ \\
\hline & IKS, 6000 Class I & & $30.0 \mathrm{~A}$ \\
\hline & $1-600 \mathrm{~A}$ & & \\
\hline MCC4Fuse 4 & BUSSMANN & JKS & $100.0 \mathrm{~A}$ \\
\hline & IKS, 600V Class I & & $1000 \mathrm{~A}$ \\
\hline
\end{tabular}




\section{Appendix B}

\section{Short Circuit Analysis}

[NOTE: Ctrl+click on the image to open the PDF file.]

THREE PHASE FAULT REPORT

(FOR APPLICATION OF LOW VOLTAGE BREAKERS)

PRE FAULT VOLTAGE: 1.0000

MODEL TRANSFORMER TAPS: NO

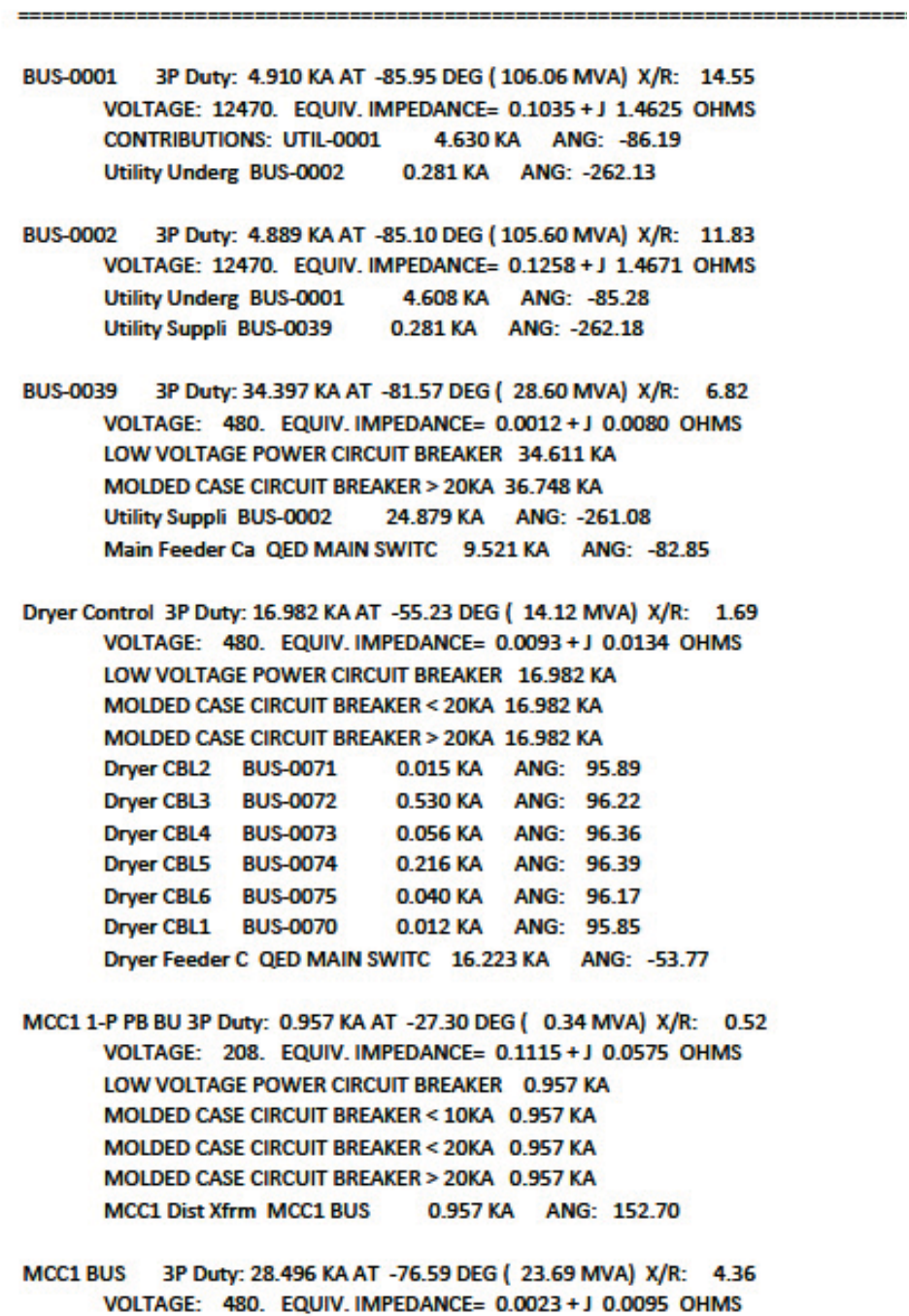




\section{Appendix C}

\section{Load Flow Analysis}

[NOTE: Ctrl+click on the image to open the PDF file.]

Mar 30, 2012 17:01:09

ALL INFORMATION PRESENTED IS FOR REVIEW, APPROVAL

INTERPRETATION AND APPLICATION BY A REGISTERED ENGINEER ONLY

SKM DISCLAIMS ANY RESPONSIBILTY AND LABILITY RESULTING

FROM THE USE AND INTERPRETATION OF THIS SOFTWARE.

SKM POWER*TOOLS FOR WINDOWS

LOAD FLOW AND VOLTAGE DROP ANALYSIS REPORT

COPYRIGHT SKM SYSTEMS ANALYSIS, INC. 1995-2011

EMar 30, $2012 \quad$ 17:01:09

PAGE 2

\begin{tabular}{|c|c|}
\hline \multicolumn{2}{|c|}{ 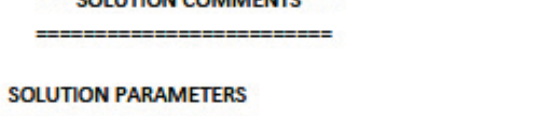 } \\
\hline BRANCH VOLTAGE CRITERIA & $: 3.00 \%$ \\
\hline BUS VOLTAGE CRITERIA & $=5.00 \%$ \\
\hline UTILTYY IMPEDANCE & :YES \\
\hline TRANSFORMER PHASE SHIFT & : NO \\
\hline LTC TRANSFORMER & : NO \\
\hline CALCULATION NETHOD & : Newton Method \\
\hline SOLUTION METHOD & : EXACT \\
\hline
\end{tabular}

ALL PU VALUES ARE EXPRESSED ON A 100 MVA BASE

LOAD FLOW IS BASED ON CONNECTED LOADS.

LOAD ANALYSIS INCLUDES ALL LOADS.

<४PERCENT VOLTAGE DROPS ARE BASED ON NOMINAL DESIGN VOLTAGES»>

SWING GENERATORS

SOURCE NAME VOLTAGE ANGLE

UTIL-0001 $1.000 \quad 0.00$ 


\section{Load Flow BUS Information}

[NOTE: Ctrl+click on the image to open the PDF file.]

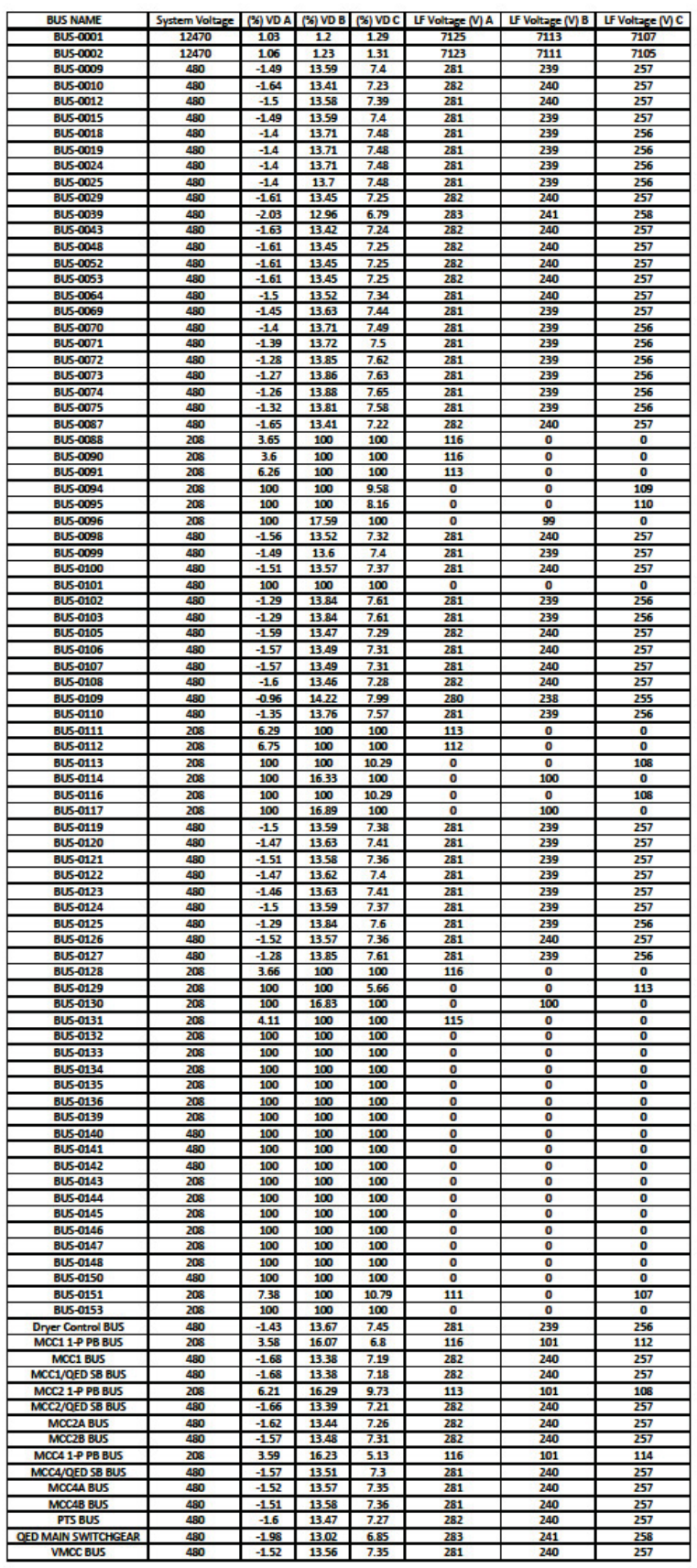




\section{Load Flow Conductor Information}

[NOTE: Ctrl+click on the image to open the PDF file.]

\begin{tabular}{|c|c|c|c|c|c|c|c|c|}
\hline \multirow{3}{*}{\begin{tabular}{|l|} 
BRANCH NAME \\
Utility Underground \\
\end{tabular}} & FROM NAME & TO NAME & INPE & Phase & $10 \%$ & & KVVA & RATING\% \\
\hline & Bus-0001 & Bus-0002 & FOR & & 0.02 & 72.4 & 5516.36 & 48.32 \\
\hline & & & & & & & & \\
\hline \multirow{2}{*}{\begin{tabular}{|l} 
Utuility Supplied \\
\end{tabular}} & Bus-0002 & sus-0039 & 1.x3 & & 3.06 & 72.4 & 516.25 & 90.76 \\
\hline & & & & & $\frac{1.17}{54}>0$ & & & $\frac{105.81}{99.6}$ \\
\hline \multirow{2}{*}{ Moci Feeder c cable } & QEDD MAIN SWITCHGEAR & MCCD/OFE SB BUS & FDR & & 20 & 566. & & \\
\hline & & & & & & & & \\
\hline \multirow[t]{2}{*}{ Mocc Feeder cable } & QEED MAIN SWTTCHGEAR & MCC2/AED SB BUS & FOR & & $\frac{0.3}{0.3}$ & $\frac{621.8}{400.0}$ & \begin{tabular}{|l|l|}
160.053 \\
13.05 \\
\end{tabular} & $\frac{44.1}{42.55}$ \\
\hline & & & & & 0.3 & $\begin{array}{ll}460.6 \\
443.0\end{array}$ & $\begin{array}{l}111.04 \\
14.37 \\
50\end{array}$ & $\begin{array}{ll}49.01 \\
4713\end{array}$ \\
\hline \multirow[t]{2}{*}{ 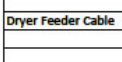 } & QED MAIN SWITCHGEAR & Dryer control & FDR & & 0.5 & 146.5 & 41.42 & \\
\hline & & & & & $\frac{0.6}{0.6}>0$ & $\frac{1723}{1606}$ & 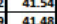 & $7499^{2}>>>3$ \\
\hline \multirow{2}{*}{ MOCA Feeder Cable } & OED MAN SWITCHGEAR & MCCA/OAED SB BUS & FDR & & 0.0 & & & \\
\hline & & & E & & 0.4. & 9021 & 217.45 & 63.98 \\
\hline \multirow[t]{2}{*}{ Main Feeder cable } & Bus-0039 & OEDD MAIN SWTTCHGGAR & FDR & & 0.0 & 18827 & 5324 & $\frac{3.006}{66.06}$ \\
\hline & & & & & acta & $\frac{2035}{2066}$ & 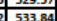 & \\
\hline \multirow{2}{*}{ Moc2 28611} & MCC2//OED SB BUS & Eus-0009 & FOR & & 0.1 .5 & & & \\
\hline & & & & & & & 4.44 & \\
\hline \multirow{2}{*}{ MOC2 $2 \mathrm{CBL}_{212}$} & 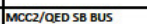 & tous-0010 & FOR & (1) & $\frac{0.9}{0 c}$ & $\frac{1.2}{17}$ & 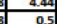 & $\frac{493}{506}$ \\
\hline & & & & & & & & 5.9 \\
\hline \multirow{2}{*}{$\mathrm{MCC2} 2 \mathrm{CBl}_{3}$} & MCCZ /OED BUS & S & - & & $0 . c$ & $\frac{1 s}{1 .}>0$ & $\frac{1}{0}$ & \\
\hline & 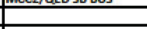 & & & & 0.0. & 2.7 & \begin{tabular}{|l|l|}
0.67 \\
\end{tabular} & $\frac{67}{7.96}$ \\
\hline \multirow[t]{2}{*}{ Moc2 CBl4 } & MCC2/EE DS B BUS & EUS-0012 & FDR & (A) & $\frac{0.0}{0.1}$ & $\frac{22}{78.8}$ & 20.621 & $\frac{7.54}{68.54}$ \\
\hline & & & E & & $\frac{0.1}{0.1}$ & 92.5 & 22221 & $\frac{80.45}{75.1}$ \\
\hline \multirow[t]{2}{*}{ MOC2 CBL5 } & MCC2/OAED SB BUS & MOC2AB BUS & FOR & & 0.0 & 77.5 & 21.85 & 33.72 \\
\hline & & & - & & 0.0 & $\frac{912}{85.0}$ & \begin{tabular}{|l|l|}
21.189 \\
21.87
\end{tabular} & 39.66 \\
\hline \multirow[t]{2}{*}{ mec2 c8st6 } & MCC2/QED SB BUS & Moc28 Bus & FDR & & 0.0 & 197.3. & \begin{tabular}{|l|l|}
55.59 \\
5.90
\end{tabular} & 51.93 \\
\hline & & & & & & & 568 & \\
\hline \multirow{2}{*}{ Moc2 2817} & MCC2//OED SB BUS & teus-0015 & FDR & & $0.1-3>$ & 15. & & \\
\hline & & & & & 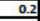 & 18. & 4.4 & 52 \\
\hline \multirow{2}{*}{ MCC2 CBL8 } & MCC2/OED SB BUS & tous-0069 & FDR & & $\frac{0.1}{0.2}+2$ & $\frac{1,2}{106}$ & & \\
\hline & & & - & & 0.2 & & -3 & 50.0 \\
\hline \multirow{2}{*}{ Mocac c8L11 } & $M C C A / O F D S B$ BUS & t & = & & 0.2 & $\frac{11}{115}$ & ]$_{1}+3$ & $\frac{46.6}{4.5}$ \\
\hline & & & F & & 0 & 18.5 & 4.44 & 5290 \\
\hline \multirow[t]{2}{*}{ MOCACBL2 } & $\begin{array}{l}M C C A / \text { OED S B BUS } \\
\end{array}$ & tous-0019 & FDR & a) & $\frac{0.1}{0.1}$ & $\frac{17.7}{15.7}$ & \begin{tabular}{|l|l|}
4.4 \\
\end{tabular} & $\frac{49.48}{45.06}$ \\
\hline & & & — & & 0.1 & $\frac{18.5}{17}$ & 4.4 .4 & $\frac{52.98}{49.4}$ \\
\hline MOCACBI5 & MCCA///E D SB BUS & MOCAA BUS & FDR & & a.c. & 396.3 & & \\
\hline & & & 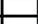 & & 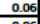 & 465.8 & 111166 & 122.55 \\
\hline MOCA C8B6 & MCCA/QED SB BUS & MCcaB Bus & FDR & & 0.0 & $\frac{354.4}{306.4}$ & 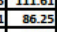 & $\frac{1143}{80.63}$ \\
\hline & & & & & . & & & \\
\hline Moc4c8677 & MCCA/OED SB BUS & tous-0024 & FOR & & $\frac{10}{0}$ & 15. & $\frac{244}{44}$ & $\frac{24}{45}$ \\
\hline & & & & & 0 & 18. & 4.44 & \\
\hline мсСа свІ8 & MCCA/OED SB BUS & tous-0025 & Fon & & 0.1 & $\frac{17}{134}$ & $\frac{4.44}{3.37}$ & \\
\hline & & & 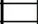 & & 0 & 15. & 3.7 & 45.0 \\
\hline Drer CBL1 & Drever control & tous-0070 & (5non & & 0.1 & 16 & 3.76 & \\
\hline & 年 & 年 & 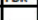 & & & & 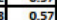 & \\
\hline & & & 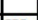 & & & & 0.57 & \\
\hline 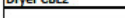 & Doryer Control & 1055:0071 & 年 & & 0.0 & 2 & 0.72 & 10.2 \\
\hline & & & - & & act & -2 & $\frac{0.72}{0.72}$ & $\frac{11}{111}$ \\
\hline Dryer CB:3 & Oryer Control & Bus-0072 & FERR & & 0.1 & 89. & 25.1 & 68. \\
\hline & & & & & $\frac{0.1}{0.1}$ & & \begin{tabular}{|l|l|}
25.11 \\
25.11 \\
\end{tabular} & \\
\hline Doper CBLA & Drver control & Bus--073 & FDR & & 0.1 & 9.4 & 267 & 379. \\
\hline & & & & & 0.1 & $\frac{\frac{11.1}{10.4}}{10}$ & \begin{tabular}{|l|}
2.67 \\
2.67
\end{tabular} & \\
\hline Dyer CB15 & Dryer Control & Bus-0074 & FDR & & 0.1 & 36.4 & 10.24 & 560.0 \\
\hline & & & & & $\frac{0.2}{0.1}$ & $\frac{42.8}{39.9}$ & $\frac{10.25}{10.25}$ & \\
\hline & MCC1/OEDSES & & & & $0.0,4$ & & 1.6 & \\
\hline
\end{tabular}




\section{Appendix D}

\section{TCC Drawings (MCC1, MCC2, Dryer, MCC4)}

[NOTE: Ctrl+click on the image to open the PDF file.]

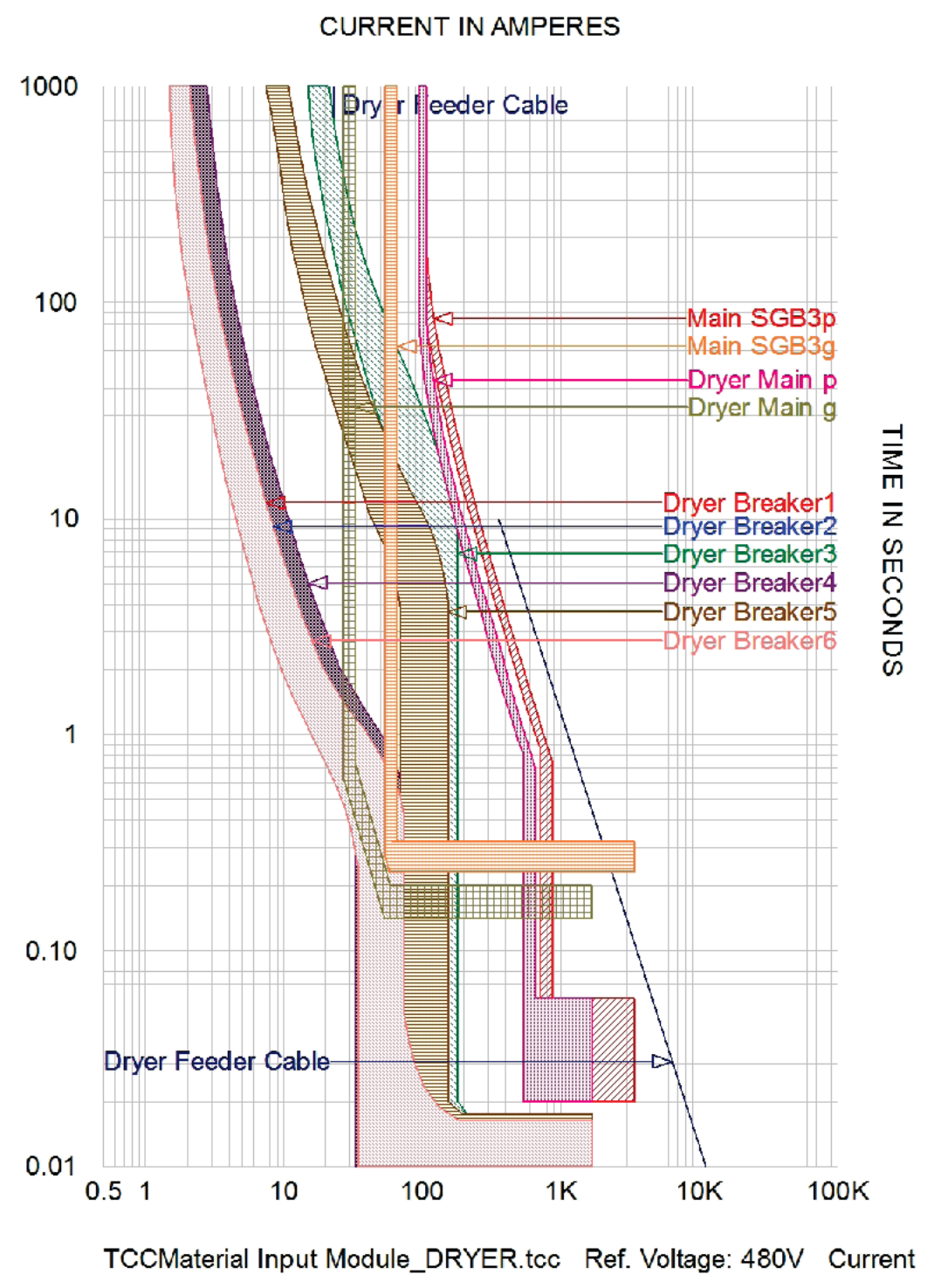




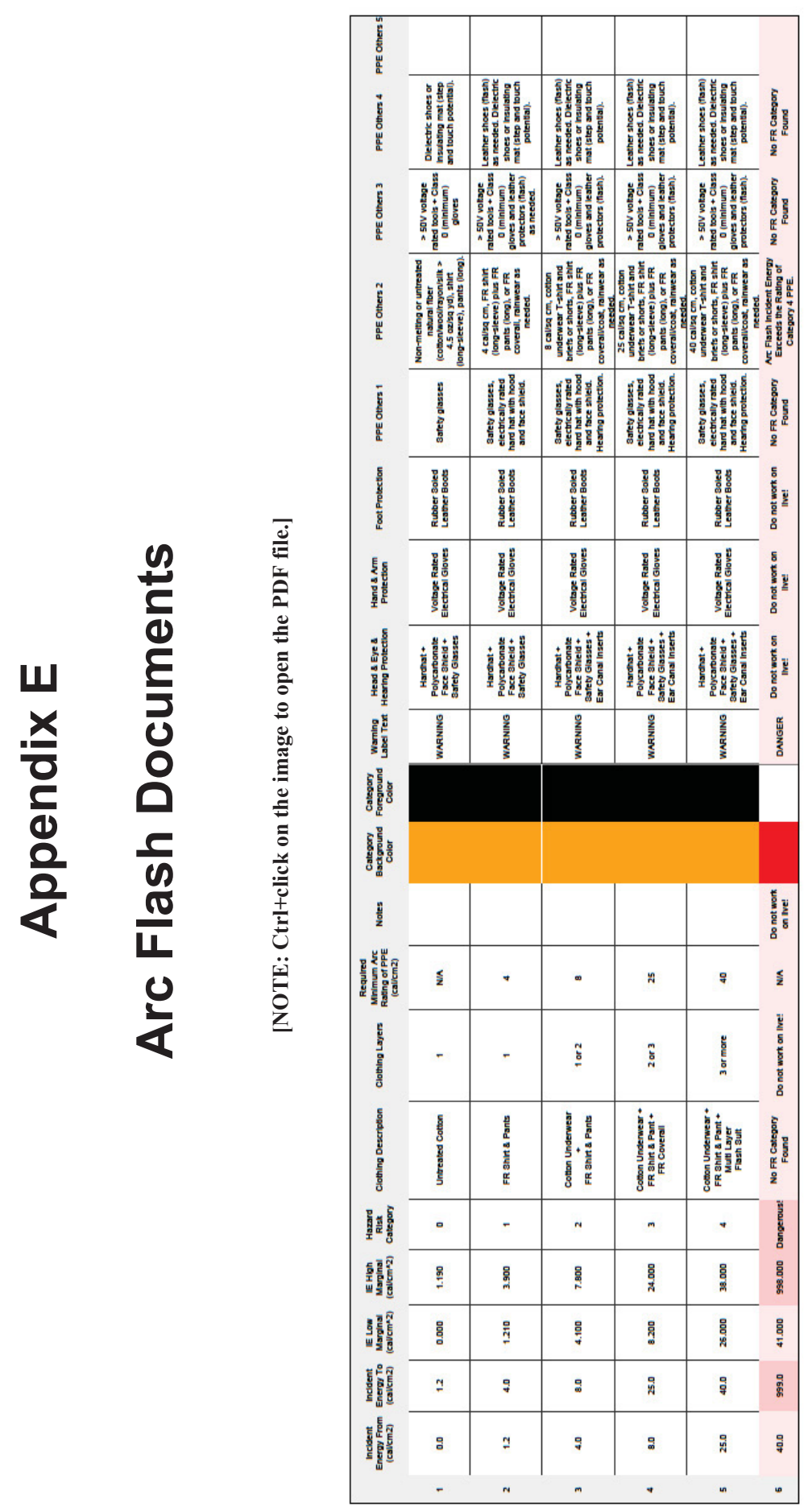




\section{Appendix F}

\section{Equipment Evaluation Reports}

[NOTE: Ctrl+click on the image to open the PDF file.]

\begin{tabular}{|c|c|c|c|c|c|c|c|c|c|c|c|}
\hline & A & $B$ & C & D & $E$ & $\mathrm{~F}$ & G & $\mathrm{H}$ & 1 & J & $\mathrm{K}$ \\
\hline 1 & Device & Status & Bus & Bus & Rated & VD\% & LF & Design & Ampactiy & LFF/ & Design\% \\
\hline \multicolumn{12}{|c|}{ Amps } \\
\hline 3 & | MCCATCBELT| & |ral & OMNCCHUS & 460 & 6000 & 0.26 & 259.23 & 301.51 & 250.0 & -112.71 & 737.05 \\
\hline 4 & Mcc1 C8L22 & Fall & VMCC BUS & 480 & 600 & 0.26 & 259.23 & "301.51 & 230.0 & 4112.71 & 131.09 \\
\hline 5 & MCC1 CBL5 & Fall & MCC1/DED SB BUS & 480 & 600 & 0.17 & -520.40 & "544.53 & 380.0 & "136.95 & 143.30 \\
\hline 6 & MCC2 C8L27 & Fall & MCC2A BUS & 480 & 600 & 0.73 & '65.07 & 75.38 & 50.0 & 730.14 & 150.76 \\
\hline \multicolumn{12}{|l|}{7} \\
\hline 8 & MCCA CBLA8 & Fall & MCCAA BUS & 480 & 600 & 0.25 & 324.01 & 376.89 & 310.0 & 704.52 & $=121.58$ \\
\hline 9 & MCCA C8L5 & Fall & MCC4/DED SB BUS & 480 & 600 & 0.06 & 4331.36 & -476.99 & 380.0 & 4113.52 & 125.52 \\
\hline 10 & MCCA CBL5O & Fall & MCC4B BUS & 480 & 600 & 0.25 & "324.04 & "376.89 & 310.0 & 704.53 & 121.58 \\
\hline 11 & MCCA CBL6 & Fall & MOC4/OED SB BUS & 480 & 600 & 0.06 & 332.18 & "384.42 & 330.0 & 87.42 & "101.16 \\
\hline \multicolumn{12}{|c|}{12} \\
\hline 13 & MCC1 Dist Ximril (PI) & Fall $(P, S)$ & MCC1 BUS & 480 & 480 & 3.70 & 74.92 & 71.25 & 10.8 & 737.83 & 703.90 \\
\hline 14 & MCC2 Dist Ximmo (PI) & Fall $(P, S)$ & MOC2B BUS & 480 & 480 & T.62 & 27.79 & 21.46 & 10.8 & 256.69 & 198.24 \\
\hline 15 & Utilly Supplled XFMR (PI) & Fall $(P, S)$ & BUS-0002 & $\overline{12470}$ & 12470 & 4.91 & 79.14 & 76.31 & 79.9 & 99.09 & 95.55 \\
\hline 16 & 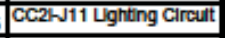 & Fall & BUS-0111 & 208 & 200 & 71.54 & 2.49 & & & & \\
\hline \multicolumn{12}{|c|}{\begin{tabular}{l|l}
17 & \\
\end{tabular}} \\
\hline 18 & Control Traller & Fall & QUS-0151 & 208 & 208 & 74.35 & 28.02 & & & & \\
\hline 19 & Decomp Module & Fall & BUS-0095 & 208 & 200 & -11.65 & 18.11 & & & & \\
\hline 20 & Dryer Module & Fall & BUS-0091 & 208 & 200 & -11.51 & 18.08 & & & & \\
\hline 21 & Dryer Moduleo & Fall & BUS-0094 & 208 & 200 & 13.12 & 18.42 & & & & \\
\hline \multicolumn{12}{|c|}{22} \\
\hline 23 & Metering Bln & Fall & BUS-0116 & 208 & 200 & 73.86 & 18.57 & & & & \\
\hline 24 & Miling Module & Fall & BUS-0112 & 208 & 200 & -12.03 & 18.19 & & & & \\
\hline 25 & Miling Modu'eo & Fall & BUS-0113 & 208 & 200 & -13.86 & 18.57 & & & & \\
\hline \multicolumn{12}{|l|}{26} \\
\hline \multirow{2}{*}{\multicolumn{12}{|c|}{28 ('LF Amps) Device did not pass. De }} \\
\hline & & & & & & & & & & & \\
\hline & ('Design Amps) Device & anot pas & Device is eflit & & or $\mathrm{F}$. & alled $(10)$ & & econtit & scurren & ppactit & \\
\hline
\end{tabular}




\section{Appendix G}

\section{Electrical Inspection Emails}

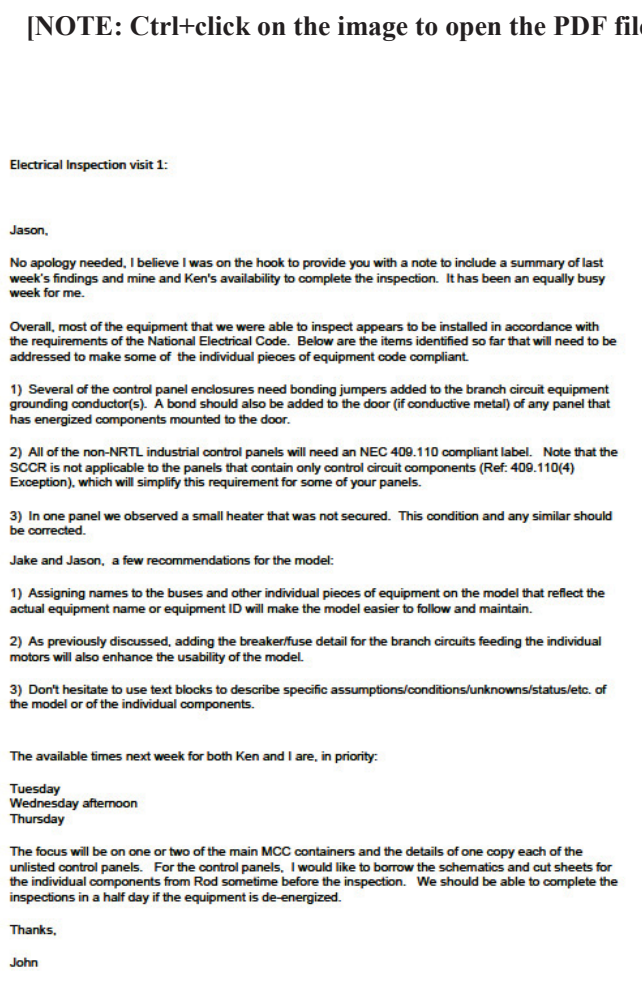




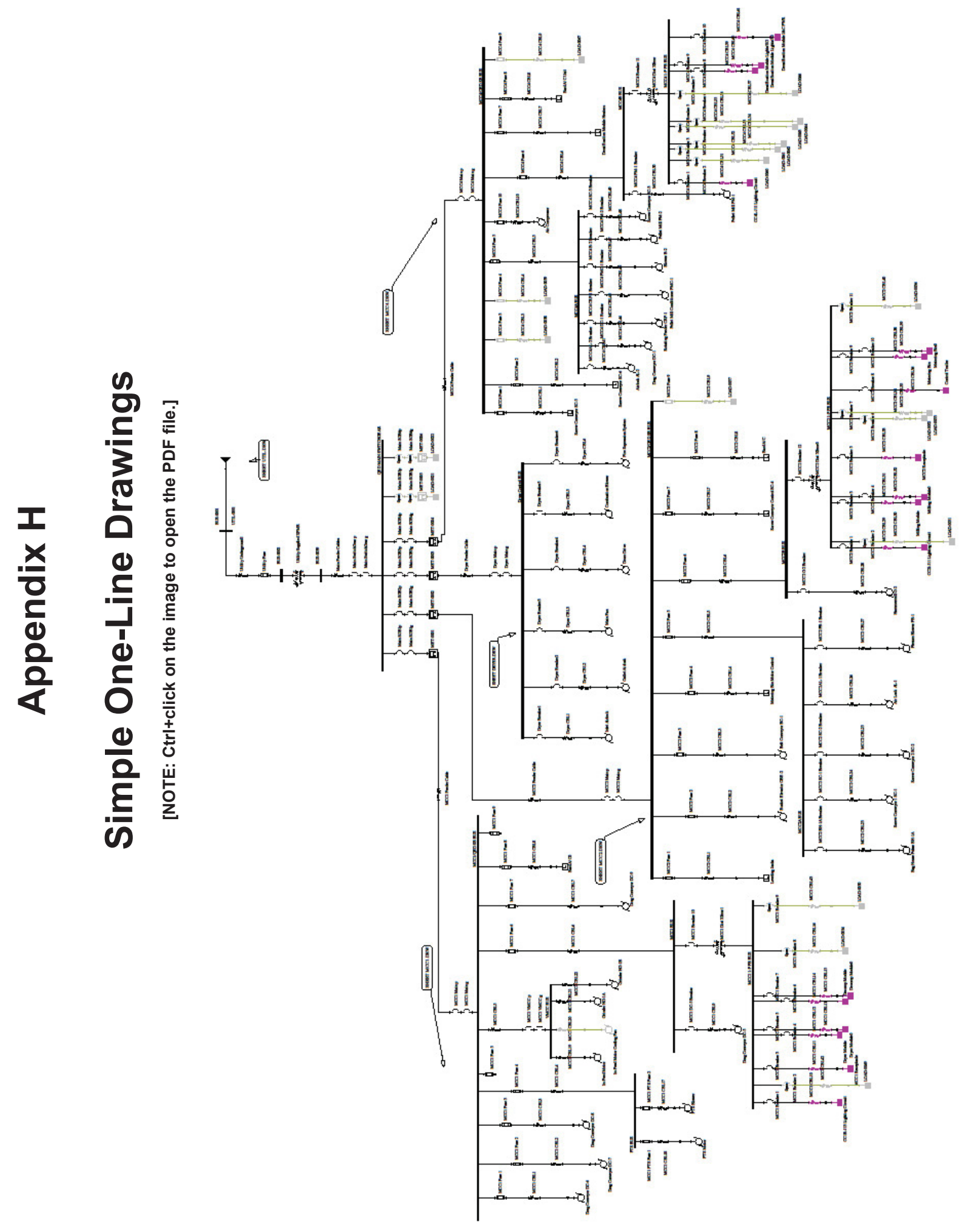




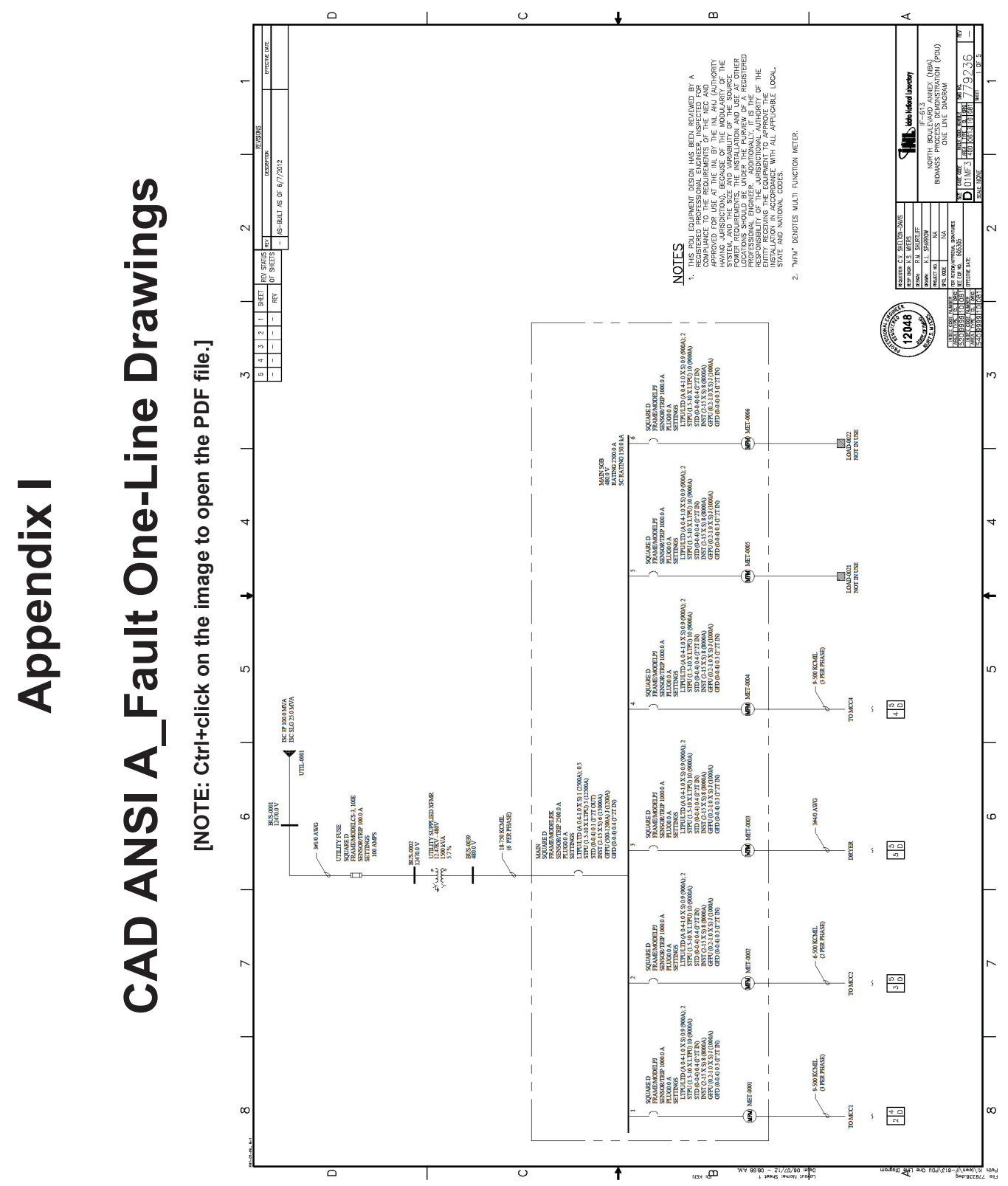

